\title{
High Temperature Materials Interim Data Qualification Report FY 2011
}

Nancy Lybeck

The INL is a

U.S. Department of Energy

National Laboratory

operated by

Battelle Energy Alliance

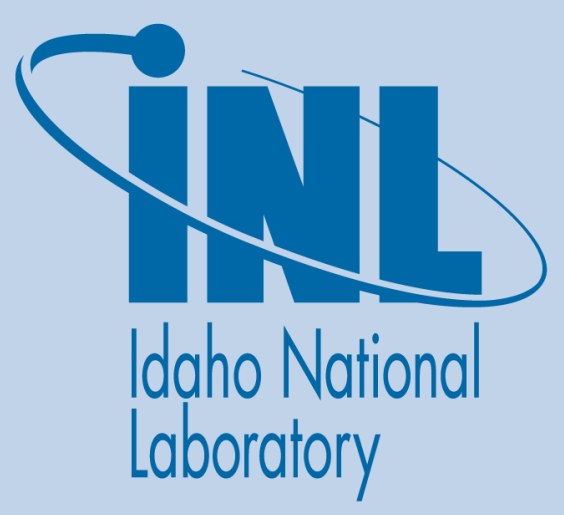

August 2011

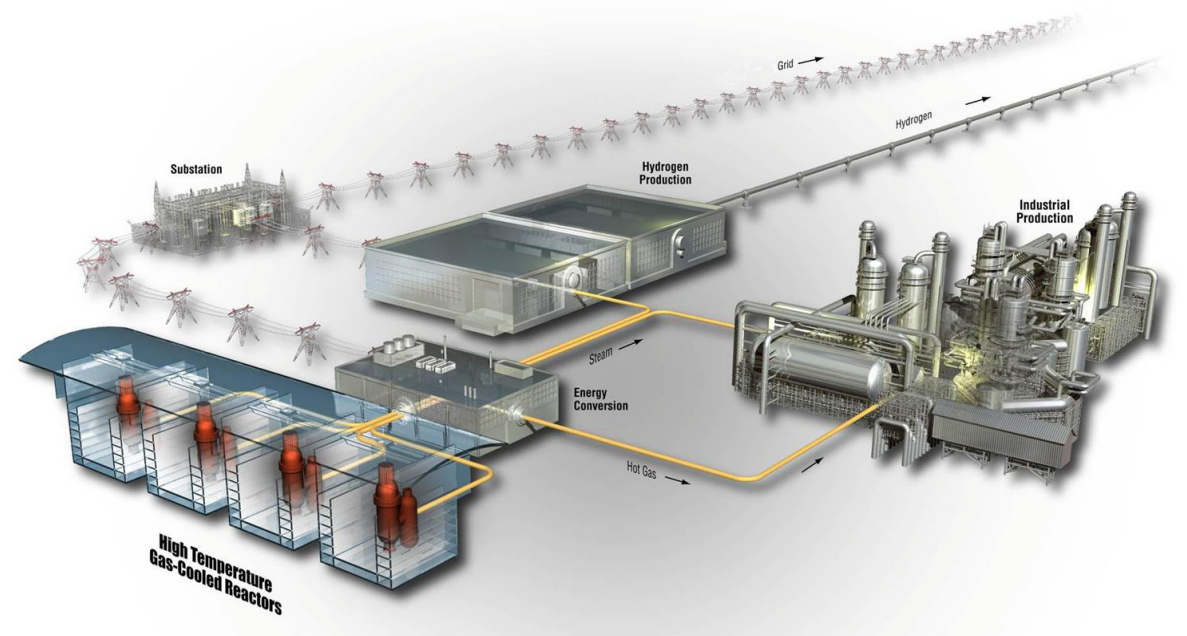




\section{DISCLAIMER}

This information was prepared as an account of work sponsored by an agency of the U.S. Government. Neither the U.S. Government nor any agency thereof, nor any of their employees, makes any warranty, expressed or implied, or assumes any legal liability or responsibility for the accuracy, completeness, or usefulness, of any information, apparatus, product, or process disclosed, or represents that its use would not infringe privately owned rights. References herein to any specific commercial product, process, or service by trade name, trade mark, manufacturer, or otherwise, does not necessarily constitute or imply its endorsement, recommendation, or favoring by the U.S. Government or any agency thereof. The views and opinions of authors expressed herein do not necessarily state or reflect those of the U.S. Government or any agency thereof. 


\title{
High Temperature Materials Interim Data Qualification Report FY 2011
}

\author{
Nancy Lybeck
}

August 2011

Idaho National Laboratory

Next Generation Nuclear Plant Project

Idaho Falls, Idaho 83415

Prepared for the

U.S. Department of Energy

Office of Nuclear Energy

Under DOE Idaho Operations Office

Contract DE-AC07-05ID14517 



\section{Next Generation Nuclear Plant Project}

\section{High Temperature Materials Interim Data Qualification Report FY 2011}

INL/EXT-11-22857

August 2011

Approved by:
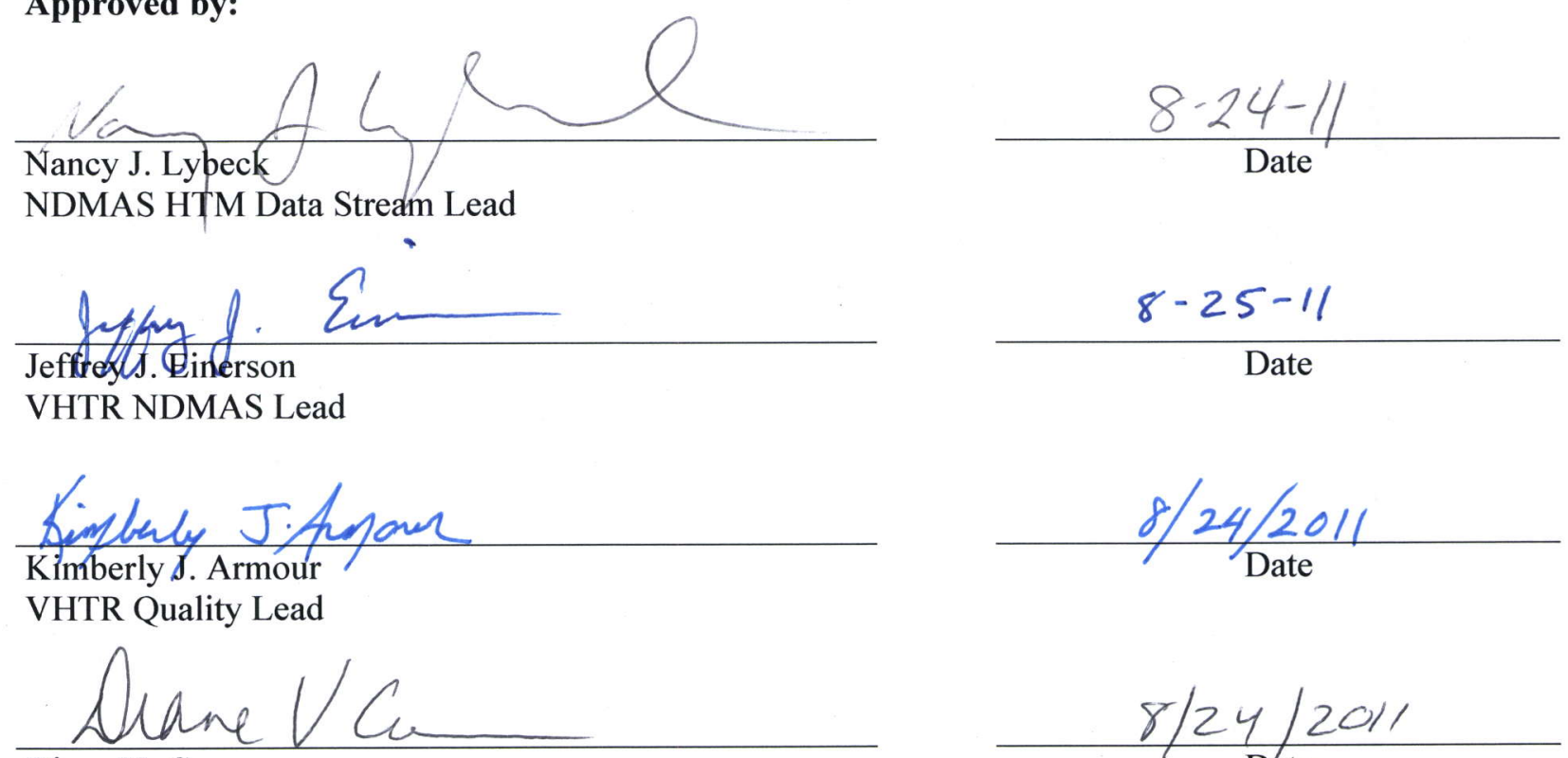

Diane V. Croson

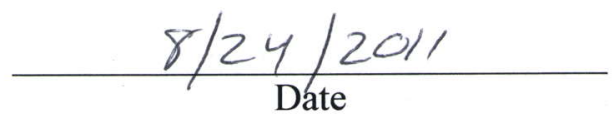

VHTR TDO Deputy Director 



\begin{abstract}
Projects for the Very High Temperature Reactor (VHTR) Technology Development Office provide data in support of Nuclear Regulatory Commission licensing of the VHTR. Fuel and materials to be used in the reactor are tested and characterized to quantify performance in high temperature and high fluence environments. The VHTR program has established the Next Generation Nuclear Plant (NGNP) Data Management and Analysis System (NDMAS) to ensure that VHTR data are qualified for use, stored in a readily accessible electronic form, and analyzed to extract useful results.

This document focuses on the first NDMAS objective - ensuring that VHTR data are qualified for use. It describes the characterization data stream for high temperature materials and the processing of these data within NDMAS, and reports the interim FY 2011 qualification status of the data. Data qualification activities within NDMAS for specific types of data are determined by the data qualification category assigned by the data generator. Data for high temperature materials are being collected under the Nuclear Quality Assurance (NQA)-1 guidelines and will thus be qualified data. The qualification activities for NQA-1 qualified data include: (1) capture testing to confirm that the data stored within NDMAS are identical to the raw data supplied, (2) accuracy testing to confirm that the data are an accurate representation of the system or object being measured, and (3) documenting that the data were collected under an NQA-1 or equivalent Quality Assurance program.

As of August 1, 2011, data from seven test series within the high temperature materials data stream have been entered into the NDMAS vault, including tensile tests, creep tests, and cyclic tests. All of the 5,603,682 records currently in the vault have been capture passed.
\end{abstract}




\section{CONTENTS}

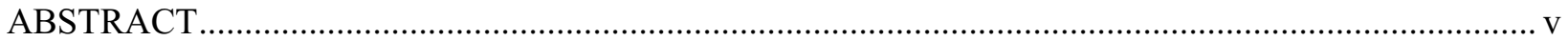

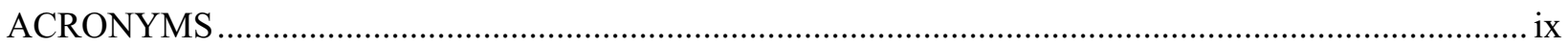

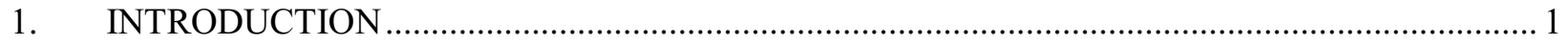

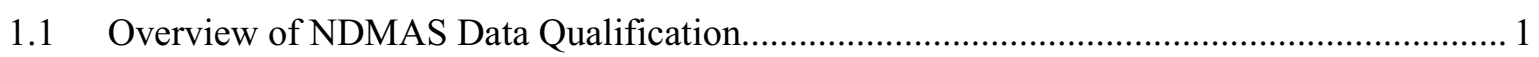

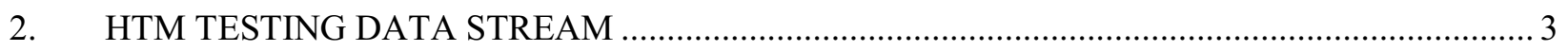

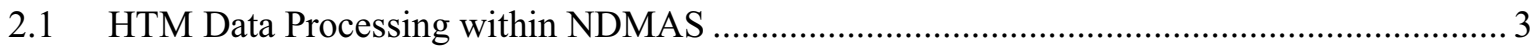

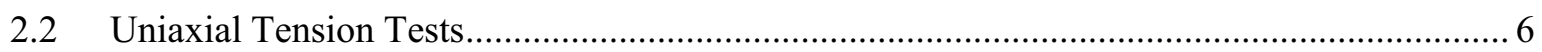

2.2.1 SG\&IHX A-1: Tensile Tests for $\mathrm{S}_{\mathrm{m}}$ Confirmatory Testing .................................... 7

2.2.2 RPV A-15: Baseline Tensile Tests of A 508/533B in Air to Address Creep

Effects on Cold Vessel........................................................................................ 9

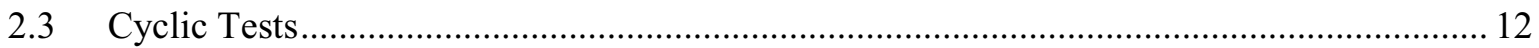

2.3.1 SG\&IHX A-20: Creep-fatigue Tests to Support Determination of Creep-

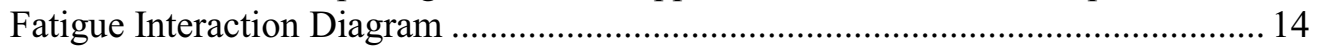

2.3.2 SG\&IHX A-3 Creep-Fatigue Tests for Alloy 617 Welds .......................................... 16

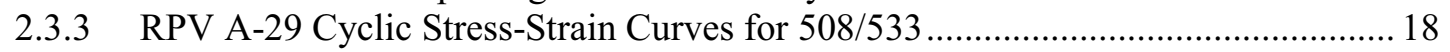

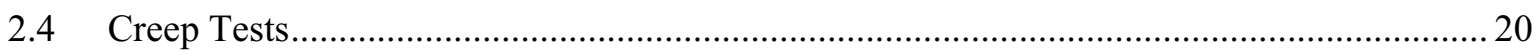

2.4.1 SG\&IHX A-13A Creep Curves to Qualify Unified Constitutive Model ................... 21

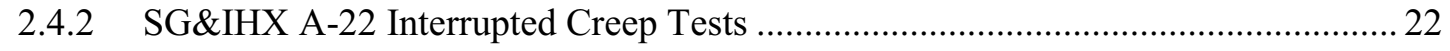

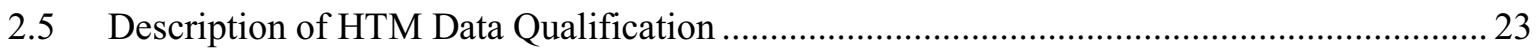

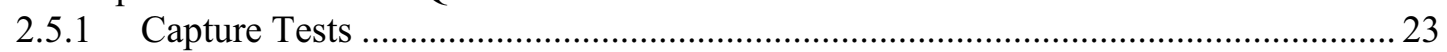

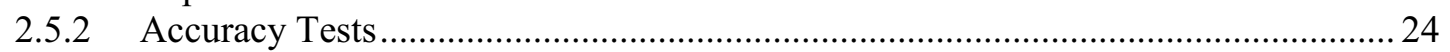

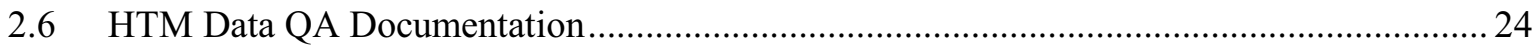

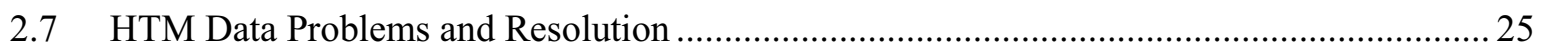

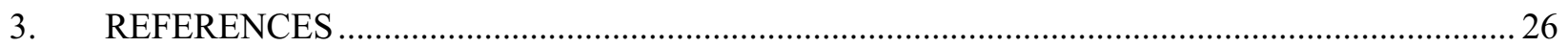

\section{FIGURES}

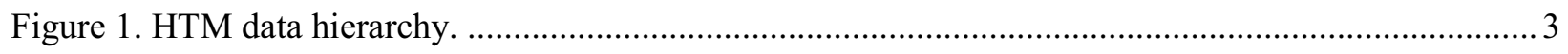

Figure 2. Stress-strain curves for tensile testing of Alloy 617 at multiple temperatures.......................... 8

Figure 3. Tensile strength values versus temperature for Alloys 617 and $800 \mathrm{H}$................................... 9

Figure 4. Stress-strain curves for Alloy A508/A533B at multiple temperatures at nominal strain rate $.001 / \mathrm{S}$.

Figure 5. Stress-strain curves for Alloy A508/A533B at multiple temperatures at nominal strain rate $8.33 \mathrm{E}-5 / \mathrm{s}$. 11

Figure 6. Tensile strength values versus temperature for Alloy A508/A533B ..................................... 12

Figure 7. Hysteresis loops for Alloy 617 with $0.3 \%$ strain and a 3 -minute hold at maximum strain......... 15

Figure 8. Peak and valley stresses versus cycle for Alloy 617 with $0.3 \%$ strain and a 3 -minute hold at maximum strain. 
Figure 9. Selected hysteresis loops for cross-welded Alloy 617 with 1\% strain and a 600 minute hold at maximum strain.

Figure 10. Peak and valley stresses versus cycle for cross-welded Alloy 617 with 1\% strain and a 600 minute hold at maximum strain. .

Figure 11. Hysteresis loops for Alloy A508/A533B with 1\% strain. ..................................................... 19

Figure 12. Peak and valley stresses versus cycle for Alloy A508/A533B with 1\% strain....................... 20

Figure 13. Results from creep-rupture tests performed on Alloy 617 ................................................. 22

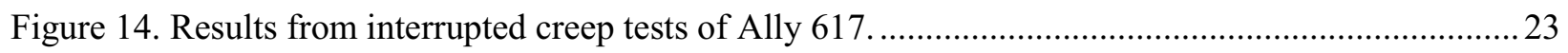

\section{TABLES}

Table 1. High temperature materials test series (Wright 2008) ....................................................... 4

Table 2. Typical parameters and classification for uniaxial tension tests............................................... 7

Table 3. NDMAS sample IDs for Dirats Tensile Test Series RPV A-15. .............................................. 10

Table 4. Typical parameters and classification for high temperature materials cyclic tests..................... 13

Table 5. Typical parameters and classification for high temperature materials creep tests...................... 21

Table 6. Qualification status of the HTM data currently entered in the NDMAS database. .....................25 


\section{ACRONYMS}

ASME American Society of Mechanical Engineers

ASTM American Society for Testing and Materials International

DAQ data acquisition

HTM high temperature materials

IHX intermediate heat exchanger

INL Idaho National Laboratory

NDMAS NGNP Data Management and Analysis System

NGNP Next Generation Nuclear Plant

NQA Nuclear Quality Assurance

QA Quality Assurance

QAPP Quality Assurance Program Plan

RPV reactor pressure vessel

RT room temperature

SG steam generator

SQL Structured Query Language

TDO Technology Development Office

VHTR Very High Temperature Reactor 


\section{High Temperature Materials Interim Data Qualification Report FY 2011}

\section{INTRODUCTION}

This report provides the interim FY 2011 status of high temperature materials (HTM) data qualification as recorded by the Next Generation Nuclear Plant (NGNP) Data Management and Analysis System (NDMAS). The HTM data experiments are a series of laboratory characterizations that address the American Society of Mechanical Engineers (ASME) code development and licensing issues identified for Alloy 617, Alloy 800H, Alloy A508, and Alloy A533B in support of the design and licensing of a very high temperature reactor (VHTR). HTM testing is expected to continue for several years.

This report gives the current data qualification status of the HTM data sets that have been processed by NDMAS.

\subsection{Overview of NDMAS Data Qualification}

NDMAS was developed to provide a single controlled repository for all NGNP data, documentation of and assistance in data qualification, advanced data analysis, and Web access to the data. A detailed discussion of the NDMAS structure and the data qualification requirements performed within NDMAS is given in the VHTR Program Data Management and Analysis Plan (Hull and Einerson 2010).

Data qualification is the act of reviewing, inspecting, testing, checking, or otherwise verifying and documenting whether data conform to specified requirements as defined by the data users and the performing organization. Depending upon the data stream, data qualification may be performed by one or more entities, including independent technical reviewers, Quality Assurance (QA) personnel, data review committees, and NDMAS staff. This process also considers whether the data were collected within an ASME Nuclear Quality Assurance (NQA) NQA-1 (2000) or equivalent approved QA program. Data qualification within NDMAS is documented as one of three qualification states-Qualified, Trend, or Failed-as follows:

1. Qualified. Data collected within an NQA-1 or equivalent QA program are independently verified to meet the requirements for a specific end use as defined in a data collection plan. Any nonconformance is concluded to not affect the usability of the data.

2. Trend. Data collected within an NQA-1 or equivalent approved QA program where the qualification process identifies minor flaws or gaps in meeting data requirements, even though the data are still considered useful by the program. Trend data captured into NDMAS are tested to verify the capture and may be subjected to some accuracy testing.

3. Failed. The data do not meet specified requirements. This may be for a number of reasons, including inadequate data collection methods, instrument failure or drift, or poor accuracy.

There may also be data types collected within the program that are only for information; these data are not qualified because specific data qualification requirements cannot be defined or independent verification is not needed or desired. These data are processed by NDMAS for display on the Web and are then archived or stored in their native file format for possible future use.

Data processing consists of capture, verification of capture, and optionally, testing for anomalies or accuracy. The capture process includes reading the raw data files, converting date/time values to Mountain Standard Time, changing measurement units to standard units, removing duplicate values, and creating $\mathrm{SAS}^{\circledR}$ datasets. Capture testing includes manual and automated checks to verify there are no 
obvious data processing errors in the source files (e.g., date/time chronology checks) and that the data stored within NDMAS are identical (or equivalent if, for example, the units have been changed) to the source data provided to NDMAS.

Optionally, tests are performed to identify anomalies. Anomalies identified by these tests are then examined with input from the technical leads and resolved to determine whether the anomalies represent instrument failures or other errors that disqualify (fail) the data or values that are unusual but reliable. The outcome of anomaly testing is tracked using an internal NDMAS accuracy pass/fail flag. Data qualification, described below, is tracked separately.

The primary component of data qualification is independent verification that data collected within an NQA-1 compliant QA program (or equivalent) meet requirements for the intended use identified in plans. The form used to document that data collection requirements were met is FRM-1073. Within the VHTR program, the NQA-1 data collection requirements are implemented through the VHTR Technology Development Office (TDO) Quality Assurance Program Plan (QAPP; Roberts and Trost 2009). NDMAS stores references to the reports that document the conformance of the specific data collection activities to the NQA-1 requirements, and tracks the qualification status of each stored value using a data qualification flag. The relevant documents that specify NQA-1 requirements and conformance for each type of testing within the HTM data stream are given in Section 2.5 of this report. 


\section{HTM TESTING DATA STREAM}

Today's high temperature alloys and associated ASME codes for reactor applications are approved up to $750^{\circ} \mathrm{C}$. However, some primary system components for the VHTR, such as the intermediate heat exchanger (IHX), will require the use of materials that can withstand higher temperatures. The thermal, environmental, and service life conditions of the NGNP will make the selection and qualification of some high temperature materials a significant challenge.

A number of NGNP Materials Research and Development (R\&D) objectives are specifically related to materials for high temperature applications, including the steam generator (SG), IHX, core barrel, and core internals such as the control rod sleeves. Research is needed to develop improved high temperature design methodologies for high temperature metallic alloys. Alloy 617 has been identified as the primary candidate for the IHX, and Alloy $800 \mathrm{H}$ has been identified as the primary candidate for the SG. Current data and models are inadequate for these alloys, and the codes and standards need to be amended and expanded. Improved understanding and models may be needed for the environmental effects and thermal aging of these high-temperature alloys. Welding and joining procedures must be also be developed, evaluated, and certified for the various materials and components, including very thick plates and thin sheets. These activities are described in INL PLN-2804 (Wright 2010a).

Additional NGNP Materials R\&D objectives are specifically related to the reactor pressure vessel (RPV). Based on vendor recommendations, along with early research results, low-alloy steels A508/A533, commonly used in conventional light water reactors, have been identified as the most promising materials for the NGNP RPV. The A508 Grade 3 and A533 materials are in the nuclear RPV section of the ASME code for temperatures less than $371^{\circ} \mathrm{C}$, however additional testing is required to accommodate longer life and, depending on the reactor design, higher temperatures. Confirmatory testing is required to address issues with long-term creep and creep-fatigue behavior. Data on long-term aging effects is needed to supplement existing data, and data are needed on the effects of impure helium on the long-term corrosion and mechanical properties of the material. There are also potential irradiation effects to be considered. These activities are described in INL PLN-2803 (Wright 2010b).

Each test series listed in Table 1 consists of multiple experiments. In this document, the name of the test series and the associated applicationSG\&IHX for tests outlined in PLN-2804 and RPV for tests outlined in PLN-2803 - will be used for identification purposes (e.g., SG\&IHX A-1). All data are being collected under NQA-1 guidelines. There are multiple sets of experiments ongoing at this time. To date, data from seven test series have been pushed to the NDMAS data vault: SG\&IHX test series A1, A-3, A-13a, A-20 and A-22, and RPV test series A-15 and A-29.

\subsection{HTM Data Processing within NDMAS}

Prior to capturing the data in NDMAS, a hierarchical data structure based on experiments was created to make the data easier to process and analyze. In particular, the HTM data need to be easily queried by experiment and by alloy. Components in NDMAS are related to each other by an assembly tree. The assembly tree for HTM is a simple hierarchical structure, presented in Figure 1. The sample name should include the alloy to enable the ability to query by alloy. Note that it is not necessary to include the associated research plan with the test series, because the alloy uniquely identifies the research plan.

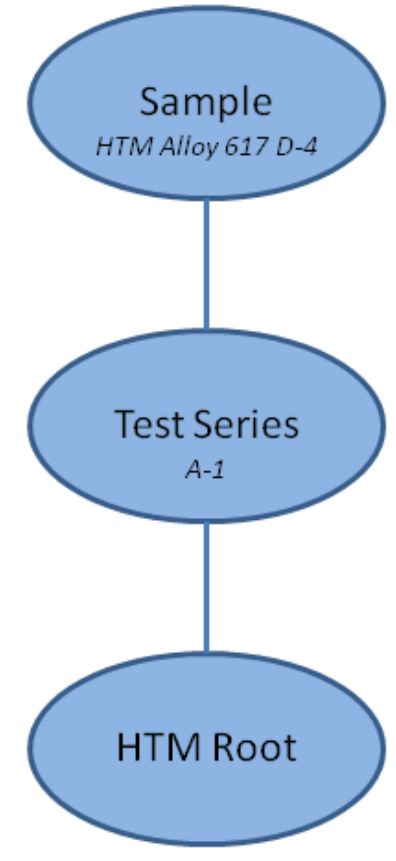

Figure 1. HTM data hierarchy. 
Data processing and storage within NDMAS occurs via the following process. Raw data files covering one test series (e.g., RPV A-1) are periodically placed in the appropriate subdirectories of the folder $\backslash$ Fserob1 $\backslash$ projects $2 \backslash N D M A S$, creating a data package. A batch file is run to copy the new data files to the NDMAS data archive and to update an NDMAS-maintained list of files waiting processing. The data archive is part of a subversion repository, which tracks any changes made to the files after the original data transfer.

There is no fixed data transfer schedule for the HTM data stream. The timing of the transfer is left to the discretion of the data generators.

The type and amount of incoming data varies for each test series. Because it is anticipated that similar test series listed in Table 1 will result in similar output data, more specific information is provided in the following sections based on the type of testing. Although there are multiple types of tests scheduled to be performed, only uniaxial tension tests, creep tests, and cyclic tests are currently stored in the vault. All of the data processing is accomplished using SAS Enterprise Guide ${ }^{\circledR}$ software projects. The project codes used to process the data are maintained under version control.

Table 1. High temperature materials test series (Wright 2010a, Wright 2010b).

Test Series Description

\section{SG\&IHX: PLN-2804}

A-1 Tensile Tests for $\mathrm{S}_{\mathrm{m}}$ Confirmatory Testing

A-2 Weld Strength Rupture Factor Determination Test

A-3 Creep-Fatigue Tests for Alloy 617 Welds

A-4 Aging Effects on Fracture Toughness of Alloy 617 Wrought Metal

A-5 Tensile Tests to Determine Strain Rate Sensitivity in Support of Unified Constitutive Model

A-6 Torsion Tests for Validating Von Mises Criterion to Support Unified Constitutive Model

A-7 Stress Dip Tests in Support of Unified Constitutive Model

A-8 Short-term (Days) Creep Tests to Support Unified Constitutive Model

A-9 Uniaxial Ratcheting Tests to Support Unified Constitutive Model

A-10 Torsional Cycling with Constant Axial Strain to Support Unified Constitutive Model

A-11 Loading-Unloading-Creep Sequence to Support Unified Constitutive Model

A-12 Thermomechanical Cycling to Support Unified Constitutive Model

A-13(a) Creep Curves to Qualify Unified Constitutive Model

A-13(b) Stress Relaxation Tests for Qualifying Unified Constitutive Model

A-14 Uniaxial Tests on Thermally Aged Alloy 617 to Support Unified Constitutive Model

A-15 Tube Burst Tests for Alloy 617 and Alloy $800 \mathrm{H}$

A-16 Creep-Fatigue Tests for SMT Specimens

A-17 Long Term Alloy 617 Creep Rupture Tests for Qualification

A-18 Thermal Aging Tests for Strength Reduction Factors

A-19 Fatigue Tests to Support Design Curve Development in Alloy 617 Code Case

A-20 Creep-fatigue Test Matrix to Support Determination of Creep-Fatigue Interaction Diagram

A-21 Tests to Determine "C" Factor in Multiaxial Creep Rupture Strength Criterion for Alloy 617

A-22 Interrupted Creep Tests

A-23 Creep-Fatigue Saturation with Hold Time

A-24 Exploration of Creep Mechanisms for Alloy 617 


\begin{tabular}{|c|c|}
\hline Test Series & Description \\
\hline A-25 & Determination of Grain Size Rupture Factors for Alloy 617 \\
\hline A-26 & Tensile Tests Supporting Unified Constitutive Model for Alloy $800 \mathrm{H}$ \\
\hline A-27 & Weld Strength Rupture Factor for Alloy $800 \mathrm{H}$ Weldments \\
\hline A-28 & Strain Rate Effect on Yield and Tensile Strength for Alloy $800 \mathrm{H}$ \\
\hline A-29 & Exploration of Creep Mechanisms of Alloy $800 \mathrm{H}$ \\
\hline A-30 & $\begin{array}{l}\text { Qualification of Yield and Tensile Strength Reduction Factors for Alloy } 800 \mathrm{H} \text { Due to } \\
\text { Thermal Aging }\end{array}$ \\
\hline A-31 & Tests to Validate "C" Factor in Multiaxial Creep Rupture Strength Criterion for Alloy $800 \mathrm{H}$ \\
\hline \multicolumn{2}{|c|}{ RPV: PLN-2803 } \\
\hline A-1 & A 508/533B Creep Rupture Tests in air to Address Creep Effects on Cold Vessel \\
\hline A-2 & SAW Cross-Weld Creep Rupture Tests in Air to Address Creep Effects on Cold Vessel \\
\hline A-3 & A 508/533B Creep Rupture Tests in NGNP He to Address Creep Effects on Cold Vessel \\
\hline A-4 & SAW Creep Rupture Tests in NGNP He to Address Creep Effects on Cold Vessel \\
\hline A-5 & Creep Rupture Tests in Air on Fatigue-SRX Damaged A 508/533B Material \\
\hline A-6 & Creep Rupture Tests in Air on Fatigue-SRX Damaged SAW \\
\hline A-7 & $\begin{array}{l}\text { A 508/533B Long-Term Qualifying Creep Rupture Tests in Air to Address Creep Effects on } \\
\text { Cold Vessel }\end{array}$ \\
\hline A-8 & $\begin{array}{l}\text { SAW Long-Term Qualifying Creep Rupture Tests in Air to Address Creep Effects on Cold } \\
\text { Vessel }\end{array}$ \\
\hline A-9 & A 508/533B Relaxation Strength in Air to Address Creep Effects on Cold Vessel \\
\hline A-10 & SAW Relaxation Strength in Air to Address Creep Effects on Cold Vessel \\
\hline A-11 & $\begin{array}{l}\text { Relaxation Strength Tests of fatigue-SRX damaged A 508/533B in Air to Address Creep } \\
\text { Effects on Cold Vessel }\end{array}$ \\
\hline A-12 & $\begin{array}{l}\text { Relaxation Strength Tests of Fatigue-SRX Damaged SAW in Air to Address Creep Effects } \\
\text { on Cold Vessel }\end{array}$ \\
\hline A-13 & A 508/533B Fatigue-SRX Tests in Air to Address Creep Effects on Cold Vessel \\
\hline A-14 & SAW Fatigue-SRX Tests in Air to Address Creep Effects on Cold Vessel \\
\hline A-15 & Baseline Tensile Tests of A 508/533B in Air to Address Creep Effects on Cold Vessel \\
\hline A-16 & Baseline Tensile Tests of SAW in Air to Address Creep Effects on Cold Vessel \\
\hline A-17 & $\begin{array}{l}\text { Tensile Tests of Fatigue-SRX Damaged A 508/533B in Air to Address Creep Effects on } \\
\text { Cold Vessel }\end{array}$ \\
\hline A-18 & $\begin{array}{l}\text { Tensile Tests of Fatigue-SRX Damaged SAW in Air to Address Creep Effects on Cold } \\
\text { Vessel }\end{array}$ \\
\hline A-19 & $\begin{array}{l}\text { Tensile Tests of Thermally Aged A 508/533B in Air to Address Creep Effects on Cold } \\
\text { Vessel }\end{array}$ \\
\hline A-20 & Tensile Tests Thermally Aged SAW in Air to Address Creep Effects on Cold Vessel \\
\hline A-21 & $\begin{array}{l}\text { Tensile Tests of Long-Term Thermally Aged A 508/533B in Air to Address Creep Effects } \\
\text { on Cold Vessel }\end{array}$ \\
\hline A-22 & $\begin{array}{l}\text { Tensile Tests of Long-Term Thermally Aged SAW in Air to Address Creep Effects on Cold } \\
\text { Vessel }\end{array}$ \\
\hline A-23 & Baseline Toughness Measurement (Master Curve To and J-R Curve) for A 508/533B \\
\hline
\end{tabular}




\begin{tabular}{|ll|}
\hline Test Series & \\
\hline A-24 & $\begin{array}{l}\text { Toughness Measurement (Master Curve To and J-R Curve) for Fatigue-SRX Damaged A } \\
\text { 508/533B Material }\end{array}$ \\
A-25 & $\begin{array}{l}\text { Toughness Measurement (Master Curve To and J-R Curve) for Thermally Aged (20,000 hr) } \\
\text { A 508/533B Material } \\
\text { A-26 }\end{array}$ \\
& $\begin{array}{l}\text { Toughness Measurement (Master Curve To and J-R Curve) for Thermally Aged (70,000 hr) } \\
\text { A 508/533B Material }\end{array}$ \\
A-27 & Baseline Toughness Measurement (Master Curve To and J-R Curve) for SAW \\
A-28 & Baseline Toughness Measurement (Master Curve To and J-R Curve) for Heat Affected \\
A-29 & Zone of SAW \\
A-30 & A 508lic Stress-Strain Curves for 508/533 \\
A-31 & SAW Creep Rupture Tests in Air to Support Code Case N-499 \\
A-32 & A 508/533B Fatigue-SRX Tests in Air to Support Code Case N-499 \\
A-33 & SAW Fatigue-SRX Tests in Air to Support Code Case N-499 \\
A-34 & SAW Creep Rupture Tests in Air to Support Code Case N-499 \\
\hline
\end{tabular}

\subsection{Uniaxial Tension Tests}

Tensile testing involves applying increasing stress loads to a sample until it ruptures. Several uniaxial tension test series are listed in Table 1, including SG\&IXH A-1, A-5, A-14, A-18, A-26, A-28, and A-30, and RPV A-15 through A-22. Although each test series has a different goal, the tests will be performed using the same types of test rigs and will produce similar data sets.

The tensile testing procedure (Chapman and Wright 2009) outlines the method used at INL for determining the mechanical tensile properties of nominally homogeneous materials, either at room temperature or at elevated temperature. The test specimens are assumed to conform to ASTM International Standard Test Methods E8 or E21. Relevant ASTM Standards are:

- E21-09, "Standard Test Methods for Elevated Temperature Tension Tests of Metallic Materials"

- E8/E8M-08, "Standard Test Methods for Tension Testing of Metallic Materials"

- E4-09, "Standard Practice for Force Verification of Testing Machines"

- E83-06, "Standard Practice for Verification and Classification of Extensometer System"

- E220-07a, "Standard Test Method for Calibration of Thermocouples by Comparison Techniques."

The format and columns in the data sets delivered to NDMAS vary, since some of the data is collected by vendors, and as new test machines are acquired by INL. Typical data sets include the stress, strain, time, extensometer displacement, and crosshead position collected by the Data Acquisition (DAQ) system. Additionally, strength values such as ultimate tensile strength, yield strength, reduction of area, and percent elongation are tabulated for each test. The typical data columns have been categorized according to their disposition in the NDMAS system, as presented in Table 2. Variances for individual test series will be noted in subsequent subsections. 
Table 2. Typical parameters and classification for uniaxial tension tests

\begin{tabular}{|l|l|c|l|}
\hline Data Type & Response Variables and Attributes & Data Type & \multicolumn{1}{|c|}{ Disposition Category } \\
\hline Series Data & $\begin{array}{l}\text { Time } \\
\text { Stress } \\
\text { Strain }\end{array}$ & A & Capture \& Display \\
\cline { 2 - 4 } & $\begin{array}{l}\text { Actuator or Crosshead position } \\
\text { Force } \\
\text { Extensometer displacement } \\
\text { Extensometer strain } \\
\text { Estimated Strain Rate } \\
\text { Corrected strain }\end{array}$ & A & Archive \\
\hline Single Values & $\begin{array}{l}\text { Physical properties } \\
\text { Final Specimen Length } \\
\text { Test Temperature } \\
\text { Yield Strength } \\
\text { Ultimate Tensile Strength } \\
\text { Percent Elongation } \\
\text { Percent Reduction in Area }\end{array}$ & A & Capture \& Display \\
\hline Shotographs & & \\
\hline
\end{tabular}

Typically, extensometers are used to calculate strain. In cases where the range of the extensometer is less than the final percent elongation of the sample, the strain value must be calculated. Prior to saturation of the extensometer, the reported strain value is correct. After the extensometer saturates, the strain is calculated using a linear transformation based on actuator or crosshead position and the final percent elongation (reported with the summary data).

Currently, the vault contains tensile data from two test series: SG\&IHX A-1 (discussed in Section 2.2.1) and RPV A-15 (discussed in Section 2.2.2).

\subsubsection{SG\&IHX A-1: Tensile Tests for $S_{m}$ Confirmatory Testing}

The SG\&IHX A-1 tests were performed at INL. The tensile data for each experiment consists of a single Excel file. The name of the file contains a variety of information about the experiment, including the sample name, alloy, and baseline temperature. This information is not consistently contained within the file itself. The sample name is always included as part of the header information, but the other information is not. Typical file names include Alloy.617.QA.151053-D-4.700C.Charts.xls and 800H.QA.HTM10-001.H4.RT.xls (where RT stands for room temperature).

The response values required for download/display by the NDMAS system are Time, Stress, and Strain. The reported time value is the number of seconds from the beginning of the test, and has a limited column width in the data files. For the longest tests, the precision of the time column is not adequate to distinguish between successive data points. For this reason, an index is used to maintain the order of the data during processing.

There are multiple sources for strain in the input data file, and the data used are selected using the following prioritization, based on availability: corrected crosshead strain, average extensometer strain, strain from Extensometer 1, and strain from Extensometer 2. A graph of the stress-strain curves for Alloy 617 is presented in Figure 2. 


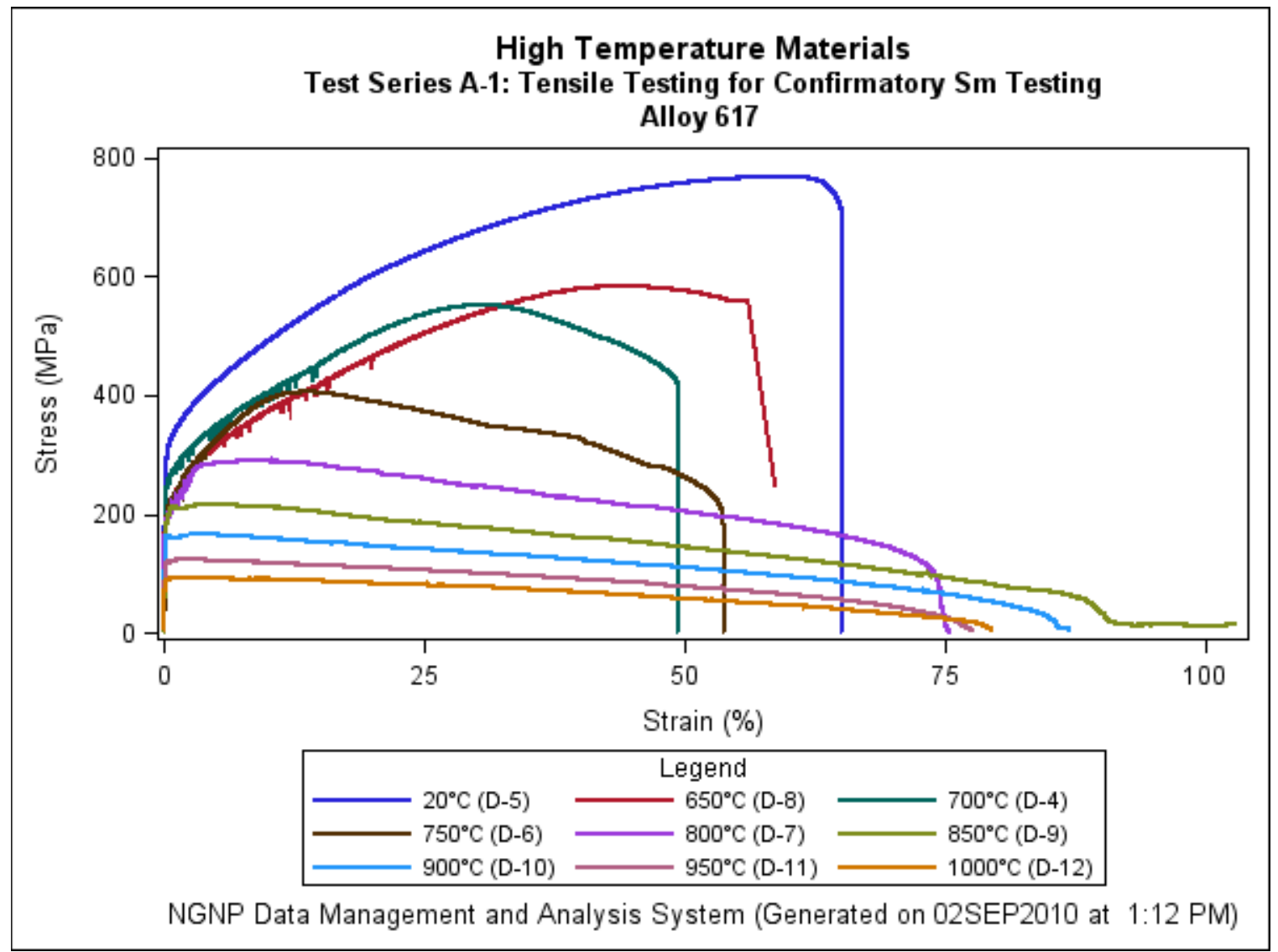

Figure 2. Stress-strain curves for tensile testing of Alloy 617 at multiple temperatures.

One data file was transmitted containing summary information from the testing (Strength.Values.800H.Alloy617.xls). This information has been inserted into the NDMAS database for download/display. Manual verification has been performed for the first data package, checking a random sample of values in the vault against the original data set. All summary values were also verified manually. A graph of the strength values by temperature and alloy is presented in Figure 3. 


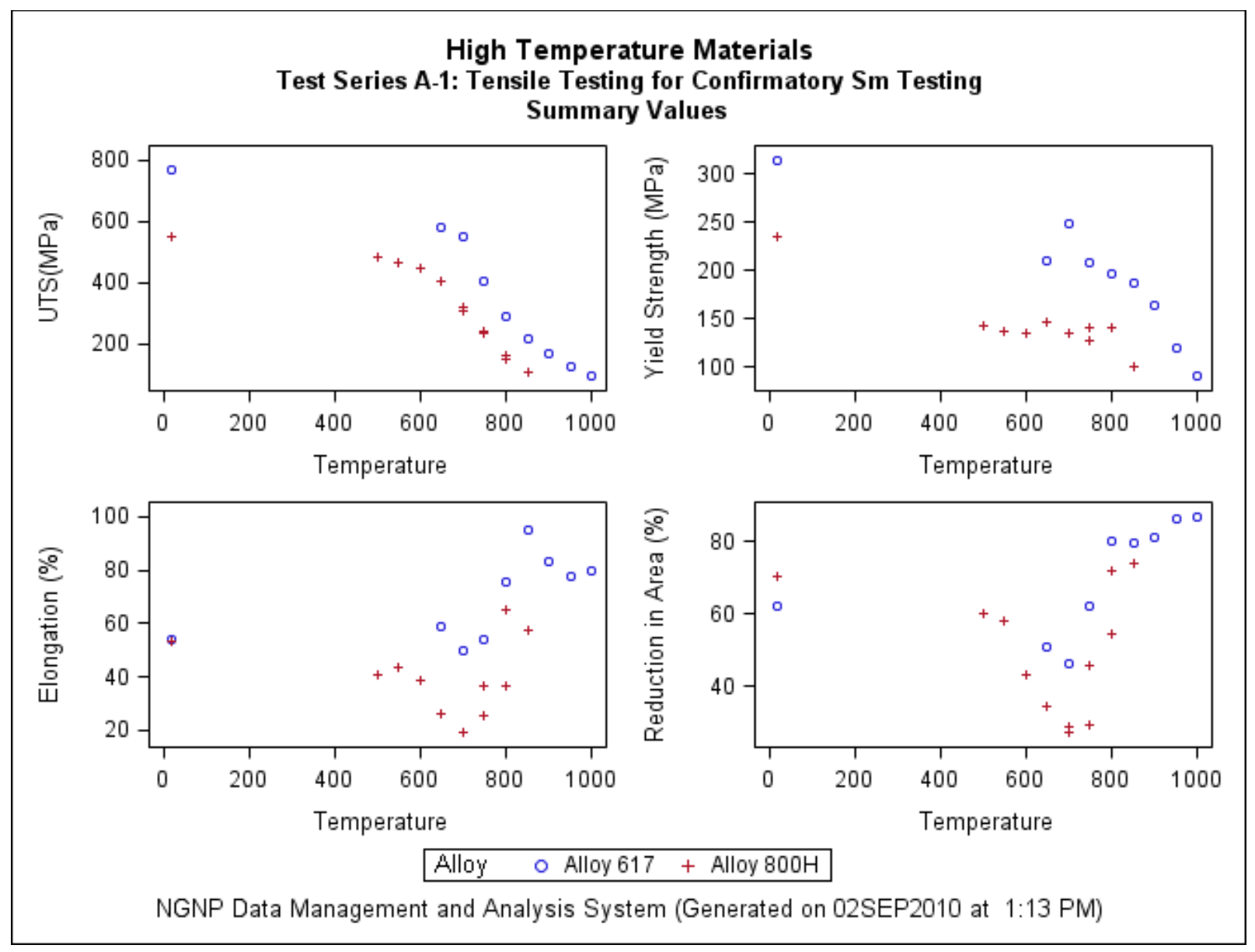

Figure 3. Tensile strength values versus temperature for Alloys 617 and $800 \mathrm{H}$.

\subsubsection{RPV A-15: Baseline Tensile Tests of A 508/533B in Air to Address Creep Effects on Cold Vessel}

The RPV A-15 tensile testing was outsourced to two separate NQA-1 qualified vendors:

Westmoreland Mechanical Testing \& Research, Inc., and Dirats Laboratories. The data collected by Dirats was generated at a nominal strain rate of $.001 / \mathrm{s}$, and the data collected by Westmoreland was generated at a nominal strain rate of $8.33 \mathrm{e}-5 / \mathrm{s}$. The data were delivered in different formats as described in the following subsections.

\subsubsection{Dirats}

The tensile data for each individual test is contained in an excel spreadsheet. The name of the file is derived from the Sample ID given in cell B2 (e.g., R519734-01-PMTET-1(0).xls corresponds to Sample ID R519734-01-1-PMTET.mss). Because the specimen ID is too long for convenient display, the sample name stored in NDMAS was generated using part of the QA number from each file. A complete listing of the assigned sample IDs is given in Table 3.

The summary and testing information are contained in A508_Tensile.xls. The specimen number listed in this table is the numeric portion of the NDMAS Sample ID. 
Table 3. NDMAS sample IDs for Dirats Tensile Test Series RPV A-15.

\begin{tabular}{|l|c|c|}
\hline \multicolumn{1}{|c|}{ Sample ID } & QA Number & NDMAS Sample ID \\
\hline R519734-01-1-PMTRT.mss & $156245-1$ & DT-1 \\
\hline R519734-01-2-PMTRT.mss & $156245-2$ & DT-2 \\
\hline R519734-01-1-PMTET.mss & $156245-3$ & DT-3 \\
\hline R519734-01-2-PMTET.mss & $156245-4$ & DT-4 \\
\hline R519734-01-3-PMTET.mss & $156245-5$ & DT-5 \\
\hline R519734-01-4-PMTET.mss & $156245-6$ & DT-6 \\
\hline R519734-01-5-PMTET.mss & $156245-7$ & DT-7 \\
\hline R519734-01-6-PMTET.mss & $156245-8$ & DT-8 \\
\hline R519734-01-7-PMTET.mss & $156245-9$ & DT-9 \\
\hline R519734-01-8-PMTET.mss & $156245-10$ & DT-10 \\
\hline R519734-01-9-PMTET.mss & $156245-11$ & DT-11 \\
\hline R519734-01-10-PMTET.mss & $156245-12$ & DT-12 \\
\hline
\end{tabular}

For this data set, the strain value must be calculated as discussed in Section 2.2, and the time, strain, extension, stress, and actuator position are stored in NDMAS and are available for download. Manual verification of a random sample from the data is complete, along with manual verification of the summary values. A graph of the stress-strain curves generated by Dirats is presented in Figure 4.

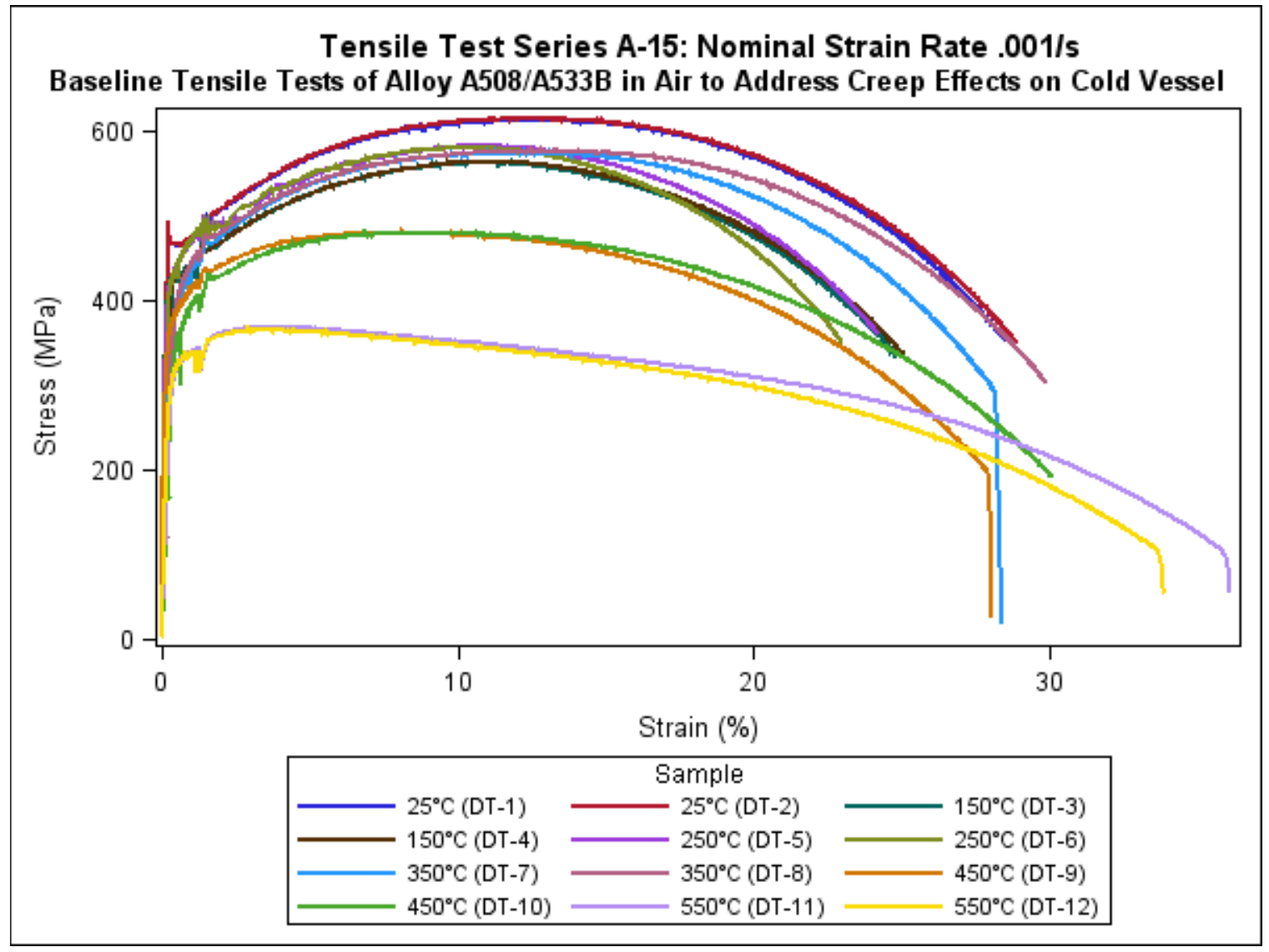

Figure 4. Stress-strain curves for Alloy A508/A533B at multiple temperatures at nominal strain rate $.001 / \mathrm{S}$. 


\subsubsection{Westmoreland}

The tensile data for each individual test is contained in a single comma-separated value file. The name of the file is the corresponding test log number (e.g., N00066.CSV). The specimen ID for each test is identified in the file 0-73809 Tensile.xls (e.g., specimen T-11 corresponds to test log N00066). The summary data and testing conditions are then read from file A508_Tensile_II.xls by looking up the specimen number, which is the numeric portion of the specimen ID.

The data columns in the individual test files are strain (in/in) and stress (ksi). Both columns were stored in the database for capture and display. The stress values were converted to MPa for consistency. Manual verification of a random sample from the data is complete, along with manual verification of the summary values. A graph of the stress-strain curves generated by Westmoreland is presented in Figure 5 . A graph of the strength values vs. temperatures from both the Dirats and Westmoreland testing is presented in Figure 6, where the Westmoreland data is represented by blue circles and the Dirats data is represented by red plus signs.

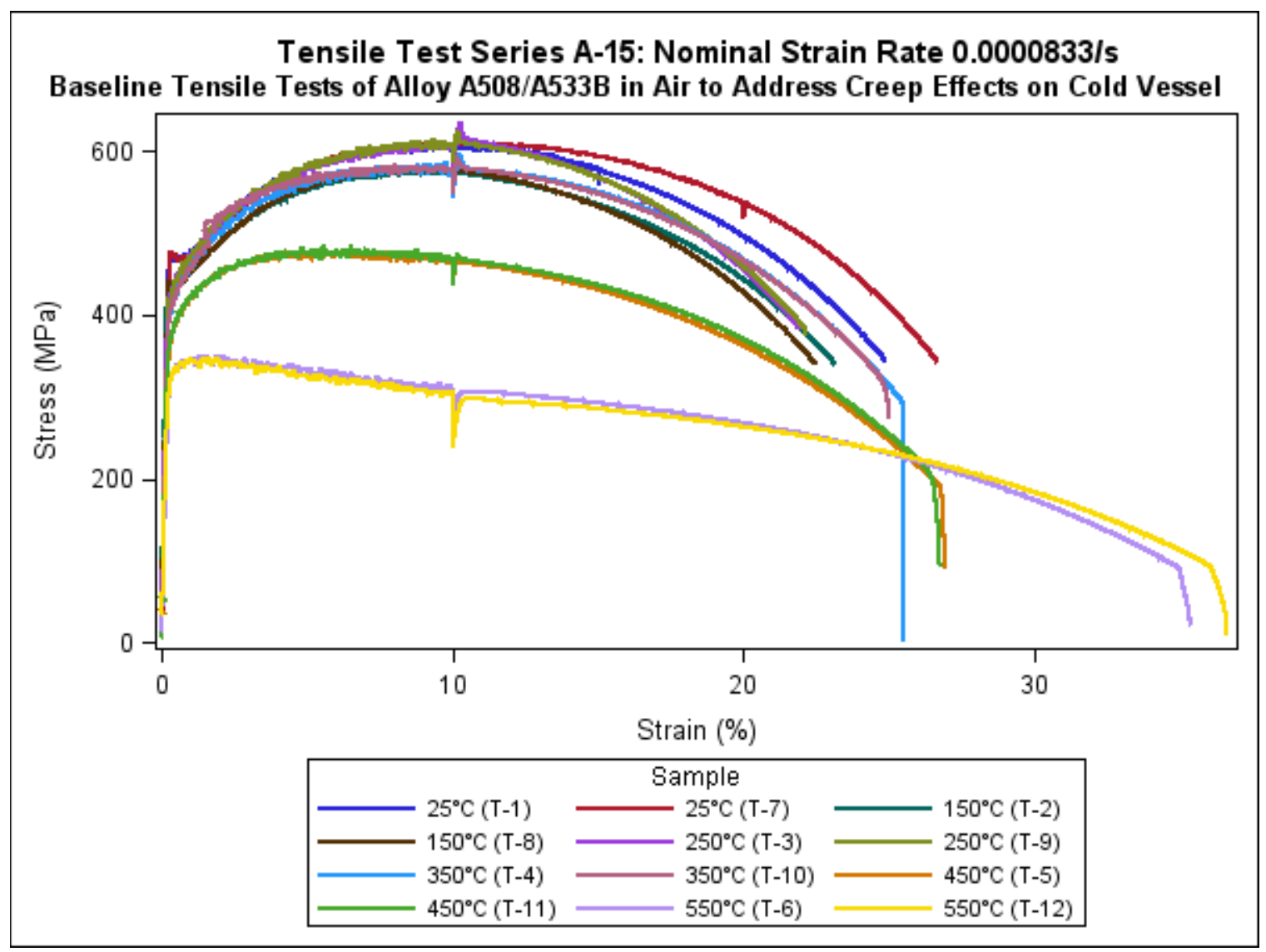

Figure 5. Stress-strain curves for Alloy A508/A533B at multiple temperatures at nominal strain rate 8.33E-5/s. 


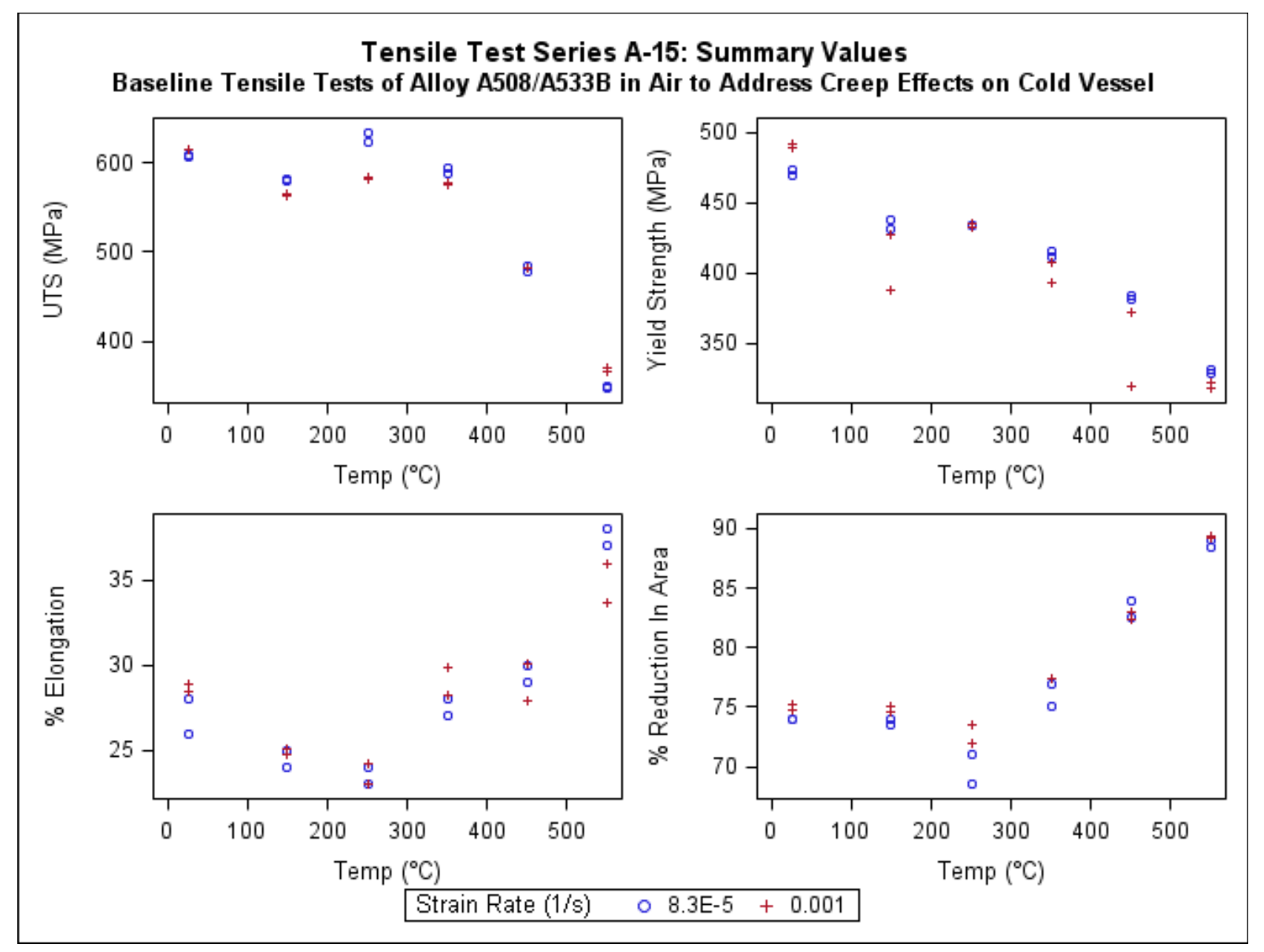

Figure 6. Tensile strength values versus temperature for Alloy A508/A533B.

\subsection{Cyclic Tests}

The creep-fatigue test procedure (Carroll and Wright 2010) applies to both continuous cycle fatigue testing and creep-fatigue testing conducted at INL. Cyclic tests listed in Table 1 include SG\&IHX A-3, A10, A-12, A-16, A-19 and A-20, and RPV A-29, A-32, A-33.

The applicable ASTM standards are:

- E 606-04, "Standard Practice for Strain-Controlled Fatigue Testing"

- E 4-09, "Standard Practice for Force Verification of Testing Machines"

- E 467-08, "Standard Practice for Verification of Constant Amplitude Dynamic Forces in an Axial Fatigue Testing System"

- E 83-06, "Standard Practice for Verification and Classification of Extensometer System"

- E 1012-05, "Standard Practice for Verification of Test Frame and Specimen Alignment"

- E 2714-09, "Standard Test Method for Creep-Fatigue Testing."

Cyclic tests involve alternately stretching and compressing a sample, generating hysteresis loops. For creep-fatigue tests, the sample is held at the maximum and/or minimum strain values of each cycle for a 
fixed time. Detailed information for each cycle is recorded by the DAQ system (time, stress, strain, temperature), along with peak and valley stress values for the cycles. Summary values are also tabulated for each test, including inelastic strain range at midlife, stable load range, initial/stable stress max, cycles for initial/stable, cycles to initiation, and cycles to failure.

The format and columns in the data sets delivered to NDMAS vary as some of the data is collected by vendors and as INL test procedures evolve. The typical data columns have been categorized according to their disposition in the NDMAS system, as presented in Table 4. Variances for individual test series will be noted in subsequent subsections. Because the DAQ system provides an overwhelming amount of stress/strain data, only specific stress-strain cycles will be stored in NDMAS. ASTM Standard 2714 indicates that, at a minimum, the logarithmic cycles should be saved: 1, 2, 5, 10, 20, 50, 100, 200, 500, etc. In the cases where the logarithmic cycles were not recorded, the closest available cycles are selected. Additional cycles will be recorded as necessary following discussions with the data generators.

Table 4. Typical parameters and classification for high temperature materials cyclic tests.

\begin{tabular}{|c|c|c|c|}
\hline Data Type & Response Variables and Attributes & Data Type & Disposition Category \\
\hline \multirow[t]{3}{*}{ Series Data } & $\begin{array}{l}\text { Time } \\
\text { Cycle } \\
\text { Corrected stress } \\
\text { Axial strain } \\
\text { Temperature } \\
\end{array}$ & A & $\begin{array}{l}\text { Capture \& Display for specific } \\
\text { stress-strain cycles only. All } \\
\text { other cycles are archived. }\end{array}$ \\
\hline & $\begin{array}{l}\text { Stress } \min / \text { max at } 2 \text { points per cycle } \\
\text { Stress ratio per cycle }\end{array}$ & $\mathrm{A}$ & Capture \& Display \\
\hline & $\begin{array}{l}\text { Axial displacement } \\
\text { Axial Force } \\
\text { Strain min/max at } 2 \text { points per cycle }\end{array}$ & A & Archive \\
\hline \multirow[t]{2}{*}{ Single Values } & $\begin{array}{l}\text { Inelastic strain range@ midlife } \\
\text { Stable load range } \\
\text { Initial/stable stress max } \\
\text { Cycles for initial/stable } \\
\text { Cycles to initiation } \\
\text { Cycles to failure }\end{array}$ & $\mathrm{A}$ & Capture \& Display \\
\hline & $\begin{array}{l}\text { Physical properties } \\
\text { Diameter at testing temperature }\end{array}$ & A & Archive \\
\hline Supporting & $\begin{array}{l}\text { Photographs } \\
\text { Procedure file }\end{array}$ & $\mathrm{A}$ & Archive \\
\hline
\end{tabular}

The time recorded at the beginning of the test is a function of the test system, and is irrelevant to the results. Therefore, prior to insertion into the vault, all times are adjusted to indicate time (in seconds) from the beginning of the test. Sometimes the time value has a limited column width in the data files. For tests with higher sampling rates, the precision of the time column is not adequate to distinguish between successive data points. For this reason, an index is used to maintain the order of the data during processing.

The vault currently contains creep-fatigue test data from test series SG\&IHX A-20 (discussed in Section 2.3.1), SG\&IHX A-3 (Section 2.3.2) and RPV A-29 (Section 2.3.3). 


\subsubsection{SG\&IHX A-20: Creep-fatigue Tests to Support Determination of Creep- Fatigue Interaction Diagram}

The SG\&IHX A-20 tests were performed at INL. There are three Excel files associated with each experiment. The specimen.xls file contains detailed data for a limited number of stress-strain cycles. The Peak Valley force file contains points of maximum and minimum strain for each cycle. The Peak Valley Strain file contains points of maximum and minimum strain for each cycle, and is for archive purposes only. The sample name is included at the beginning of the file name (e.g., B-3 specimen.xls). Summary results are delivered in the file Table A20 Results.xls.

For each logarithmic cycle, the entire stress/strain loop is saved (Time, Segment, Cycle, Strain, Stress, and Temperatures if available). In cases where the logarithmic cycles were not recorded, the closest available cycles are selected. The maximum and minimum stress values of Time, Segment, Cycle, Stress are saved for every cycle. Because the stress ratio can be calculated readily from this information, its value is not stored in the vault.

Manual verification of a random sample from the detail loop data and from the peak and valley stress data is complete for the first data package processed; manual verification of the summary values is also complete. A graph of the logarithmic cycles for sample B-6 is presented in Figure 7, and the corresponding graph of peak and valley stresses is presented in Figure 8. 


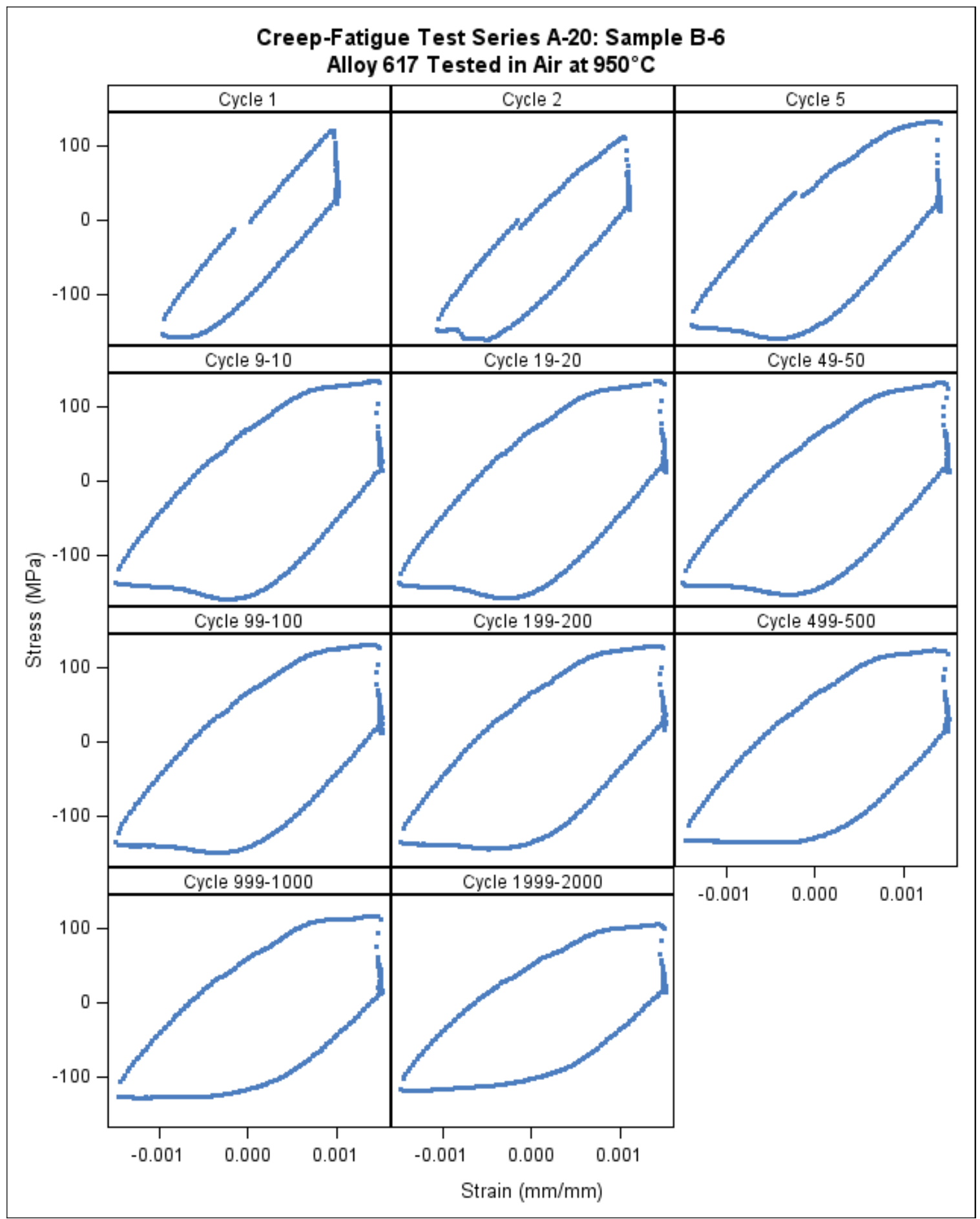

Figure 7. Hysteresis loops for Alloy 617 with $0.3 \%$ strain and a 3-minute hold at maximum strain. 


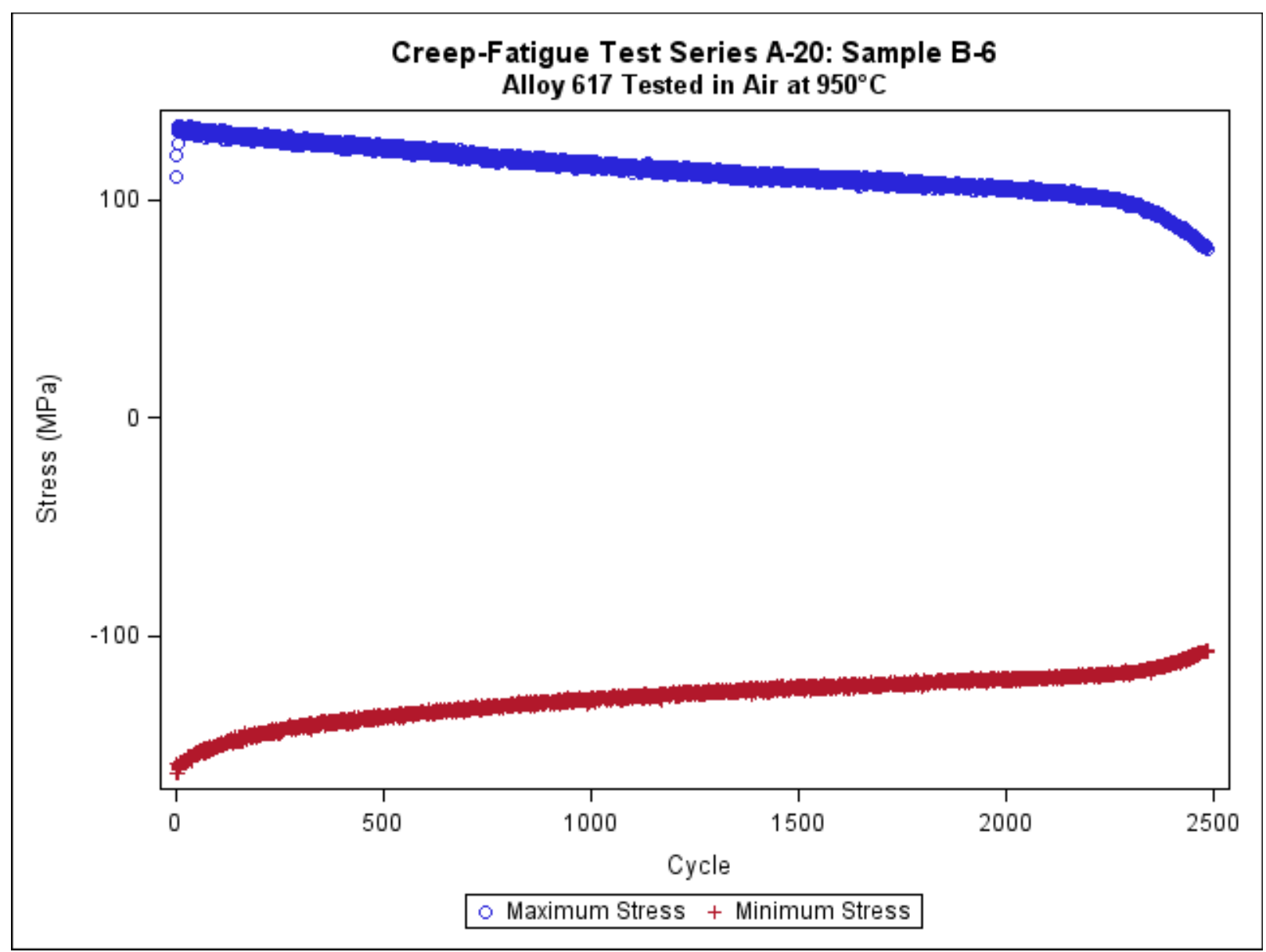

Figure 8. Peak and valley stresses versus cycle for Alloy 617 with $0.3 \%$ strain and a 3-minute hold at maximum strain.

\subsubsection{SG\&IHX A-3 Creep-Fatigue Tests for Alloy 617 Welds}

The SG\&IHX A-3 tests were performed at INL. There are two Excel files associated with each experiment. The specimen.xls file contains detailed data for a limited number of stress-strain cycles. The Peak Valley force file contains points of maximum and minimum strain for each cycle. The sample name is included at the beginning of the file name (e.g., 211-2 specimen.xls). Summary results are delivered in the file Table A3 Results.xls.

For the cross-welded Alloy 617 specimens, the number of cycles to failure is substantially smaller than for the baseline Alloy 617 specimens. Based on this, a decision was made to save the stress-strain data for additional cycles: $1-9 ; 10,20,30,40,50,60,70,80,90 ; 100,200,300,400,500,600,700,800,900$; etc. For these cycles, the entire stress/strain loop is saved (Time, Segment, Cycle, Strain, Stress, and Temperature if available). The maximum and minimum stress values (Time, Segment Cycle, Stress) are also saved for every cycle. Because the stress ratio can be calculated readily from this information, its value is not stored in the vault.

Manual verification of the data is complete. A graph of the selected cycles for sample 211-14 is presented in Figure 9, and the corresponding graph of the peak and valley stresses is presented in Figure 10. 


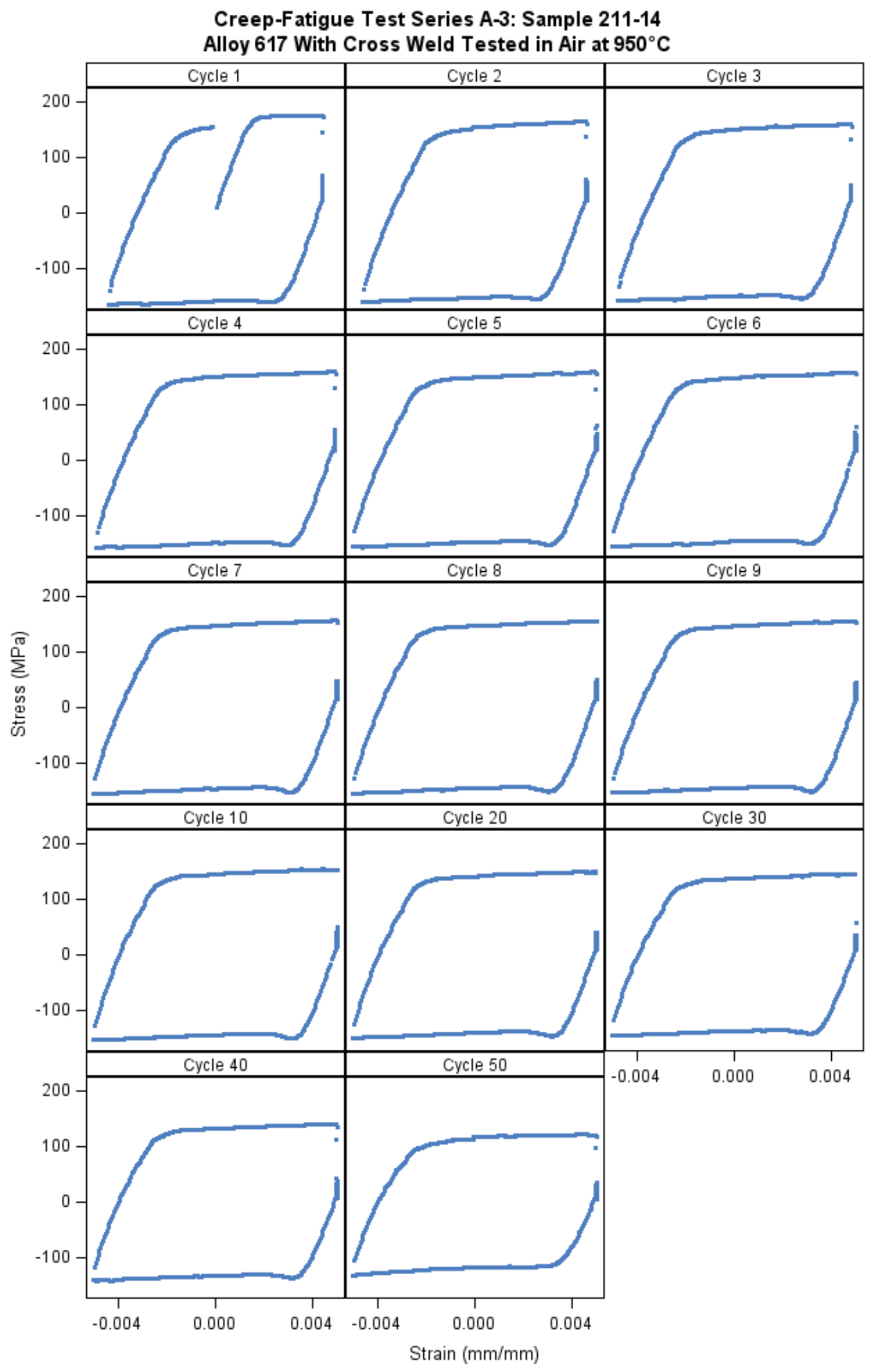

Figure 9 . Selected hysteresis loops for cross-welded Alloy 617 with $1 \%$ strain and a 600 minute hold at maximum strain. 


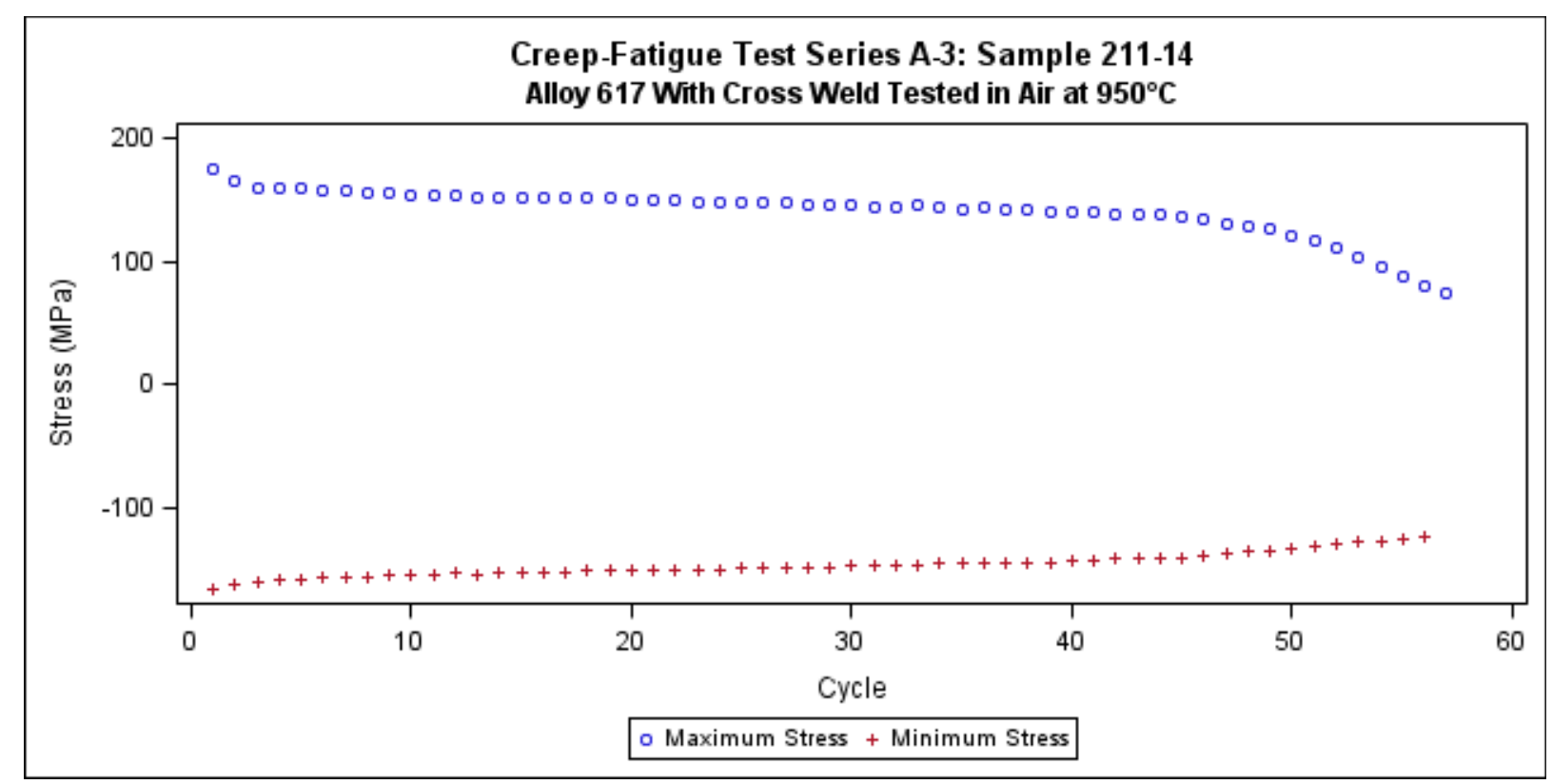

Figure 10. Peak and valley stresses versus cycle for cross-welded Alloy 617 with $1 \%$ strain and a 600 minute hold at maximum strain.

\subsubsection{RPV A-29 Cyclic Stress-Strain Curves for $508 / 533$}

The A-29 data in PLN 2803 was generated by Westmoreland Mechanical Testing \& Research, Inc., an NQA-1 qualified vendor. There are two comma-separated value data files for each sample. The file names include the Test Log Number followed by "LP" for the detailed stress-strain data and "PK" for the peak and valley stress data (e.g., M27219LP.CSV and M27219PK.CSV). Overall test results are in the Excel file Summary 0-61427.xls. The specimen ID, which is identified in the data files, is used to identify the sample in NDMAS (e.g., LCF1 for test log M27219).

In addition to the logarithmic cycles, a decision was made to store two meaningful cycles: the closest available cycles to $50 \%$ and $90 \%$ of the cycles to failure. All the reported peak and valley stress data is stored in NDMAS, however these values were not reported for all cycles.

Manual verification of the data is complete. A graph of the selected cycles for sample LCF8 is presented in Figure 11, and the corresponding graph of the peak and valley stresses is presented in Figure 12. 


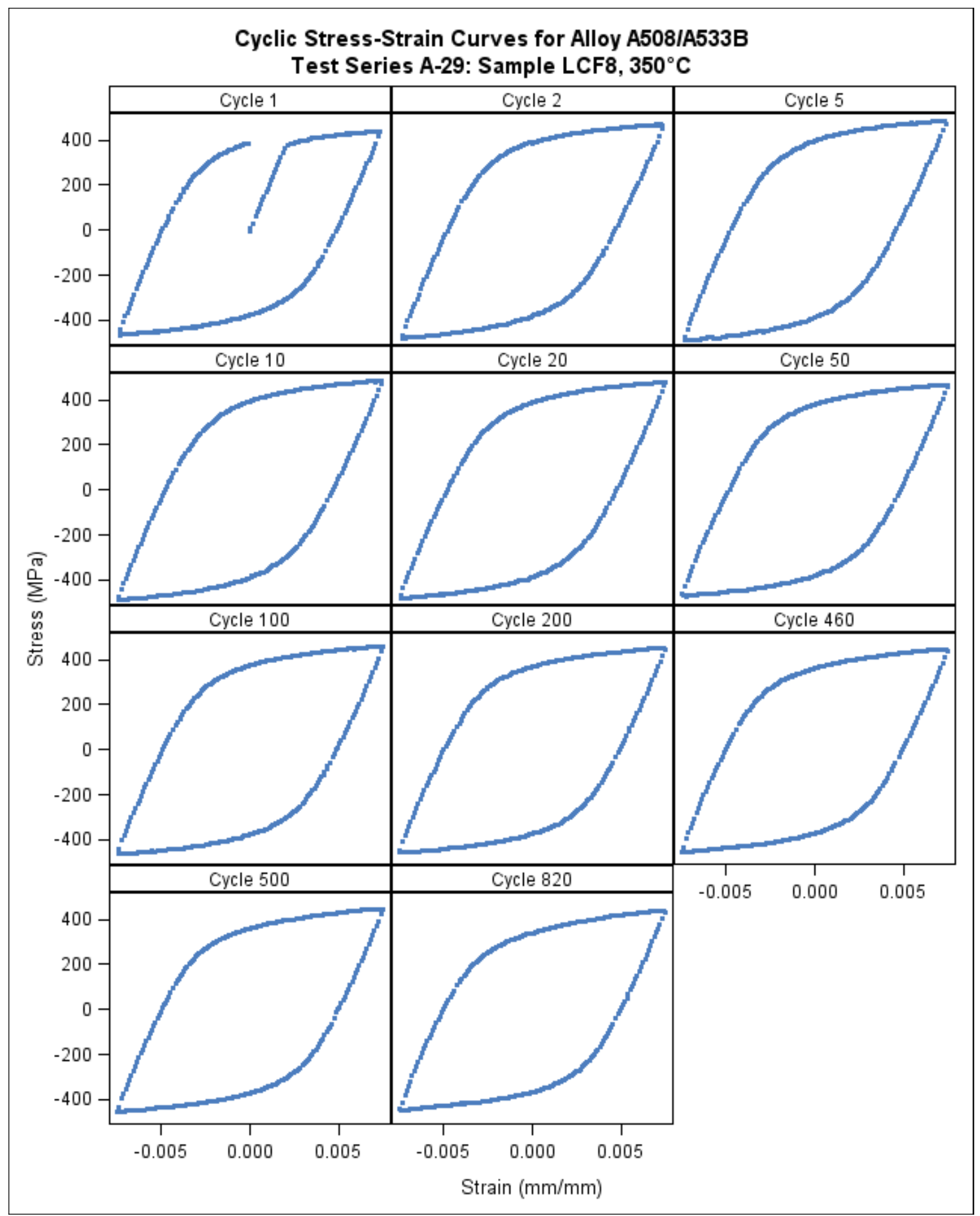

Figure 11. Hysteresis loops for Alloy A508/A533B with $1 \%$ strain. 


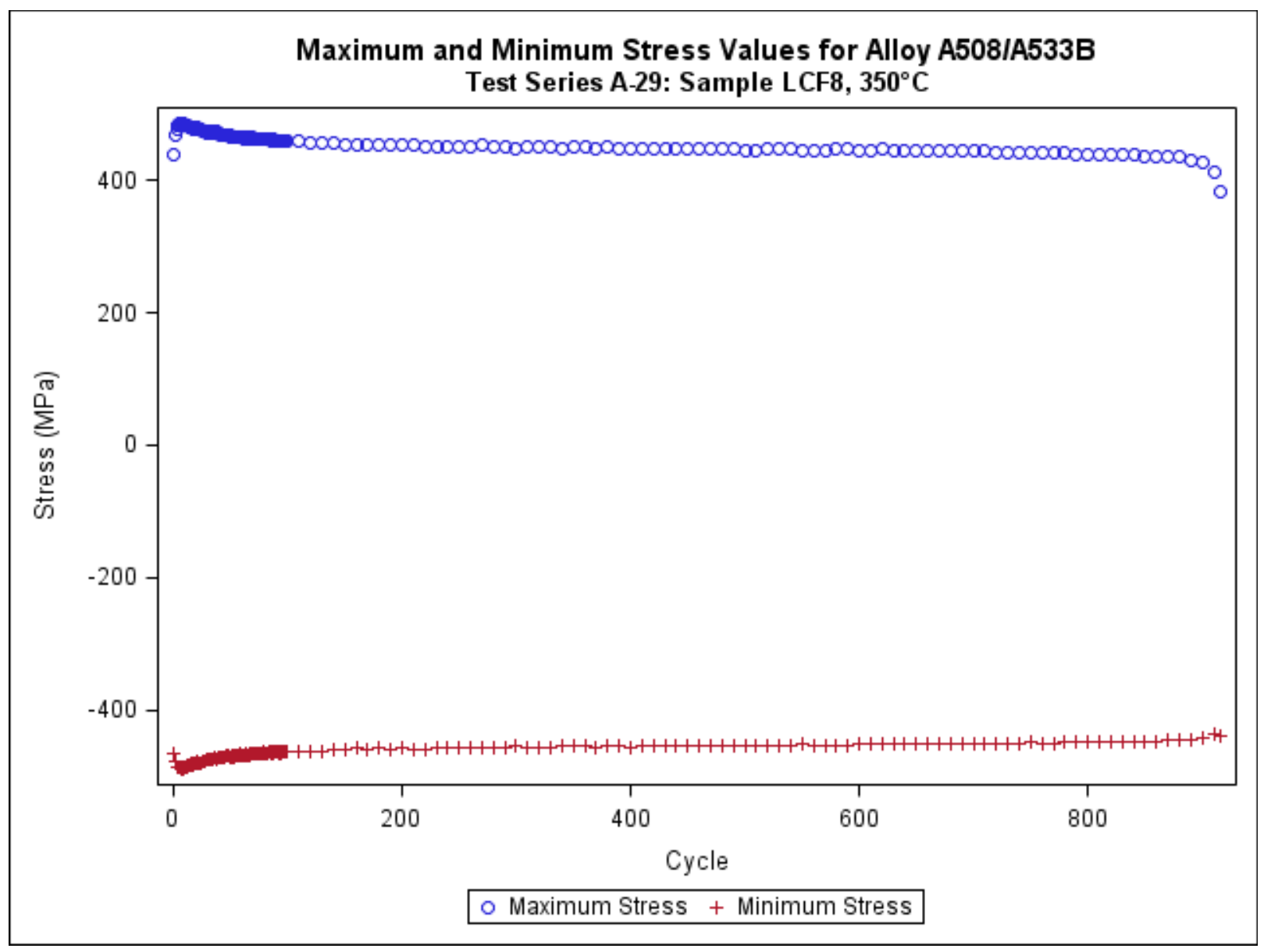

Figure 12. Peak and valley stresses versus cycle for Alloy A508/A533B with $1 \%$ strain.

\subsection{Creep Tests}

Creep tests involve applying a fixed load to a sample and recording the resulting strain values over time. Several creep test series are listed in Table 1, including SG\&IXH A-2, A-8, A-11, A-13A, A-17, A-21, A-22, A-24, A-25, A-27 and A-29, and RPV A-1 through A-8, A-30, A-31, and A-34. Although each test series has a different goal, the tests will be performed using the same types of test rigs and will produce similar data sets.

The creep procedure (Lillo and Wright 2010) applies to creep testing conducted at the INL.

The applicable ASTM standards are:

- E 139-06, "Standard Test Methods for Conducting Creep, Creep-Rupture, and Stress-Rupture Tests of Metallic Materials"

- E 8/E8M-09, "Standard Test Methods for Tension Testing of Metallic Materials"

- E 4-09, "Standard Practice for Force Verification of Testing Machines"

- E 83-06, "Standard Practice for Verification and Classification of Extensometer System"

- E 633-00, "Standard Guide for Use of Thermocouples in Creep and Stress-Rupture Testing to $1800^{\circ} \mathrm{F}$ $\left(1000^{\circ} \mathrm{C}\right)$ in Air." 
Although many different values are recorded during the test, the only values stored in NDMAS are time and strain. The typical data columns have been categorized according to their disposition in the NDMAS system, as presented in Table 5.

Table 5. Typical parameters and classification for high temperature materials creep tests.

\begin{tabular}{|c|c|c|c|}
\hline Data Type & Response Variables and Attributes & Data Type & Disposition Category \\
\hline \multirow[t]{2}{*}{ Series Data } & $\begin{array}{l}\text { Time } \\
\text { Percent creep (strain) }\end{array}$ & A & Capture \& Display \\
\hline & $\begin{array}{l}\text { Stress } \\
\text { Temperature } \\
\text { Extensometer displacement }\end{array}$ & A & Archive \\
\hline \multirow[t]{2}{*}{ Single Values } & $\begin{array}{l}\text { Temperature } \\
\text { Applied stress } \\
\text { Target percent creep }\end{array}$ & A & Capture \& Display \\
\hline & $\begin{array}{l}\text { Physical properties } \\
\text { Diameter at testing temperature }\end{array}$ & A & Archive \\
\hline Supporting & $\begin{array}{l}\text { Photographs } \\
\text { Test logs }\end{array}$ & A & Archive \\
\hline
\end{tabular}

Currently, results from two creep test series are stored in the vault: SG\&IHX A-13A (discussed in Section 2.4.1) and SG\&IHX A-22 (Section 2.4.2).

\subsubsection{SG\&IHX A-13A Creep Curves to Qualify Unified Constitutive Model}

The SG\&IHX A-13A tests were performed at INL. These tests were run until the sample ruptured. The test results for each sample tested are delivered in one file. Depending on which test frame is used, the data is either an Excel file or a comma-separated-value file. File names include the sample name as well as temperature and applied stress (e.g., G38_1000C_16MPa_rupture_final_DCK.xls and G-18, $1000 \mathrm{C}, 16 \mathrm{MPa}$, rupture.csv).

Manual verification of a random sample from the first data package processed is complete. A graph of strain versus time for sample G-22 is presented in Figure 13. 


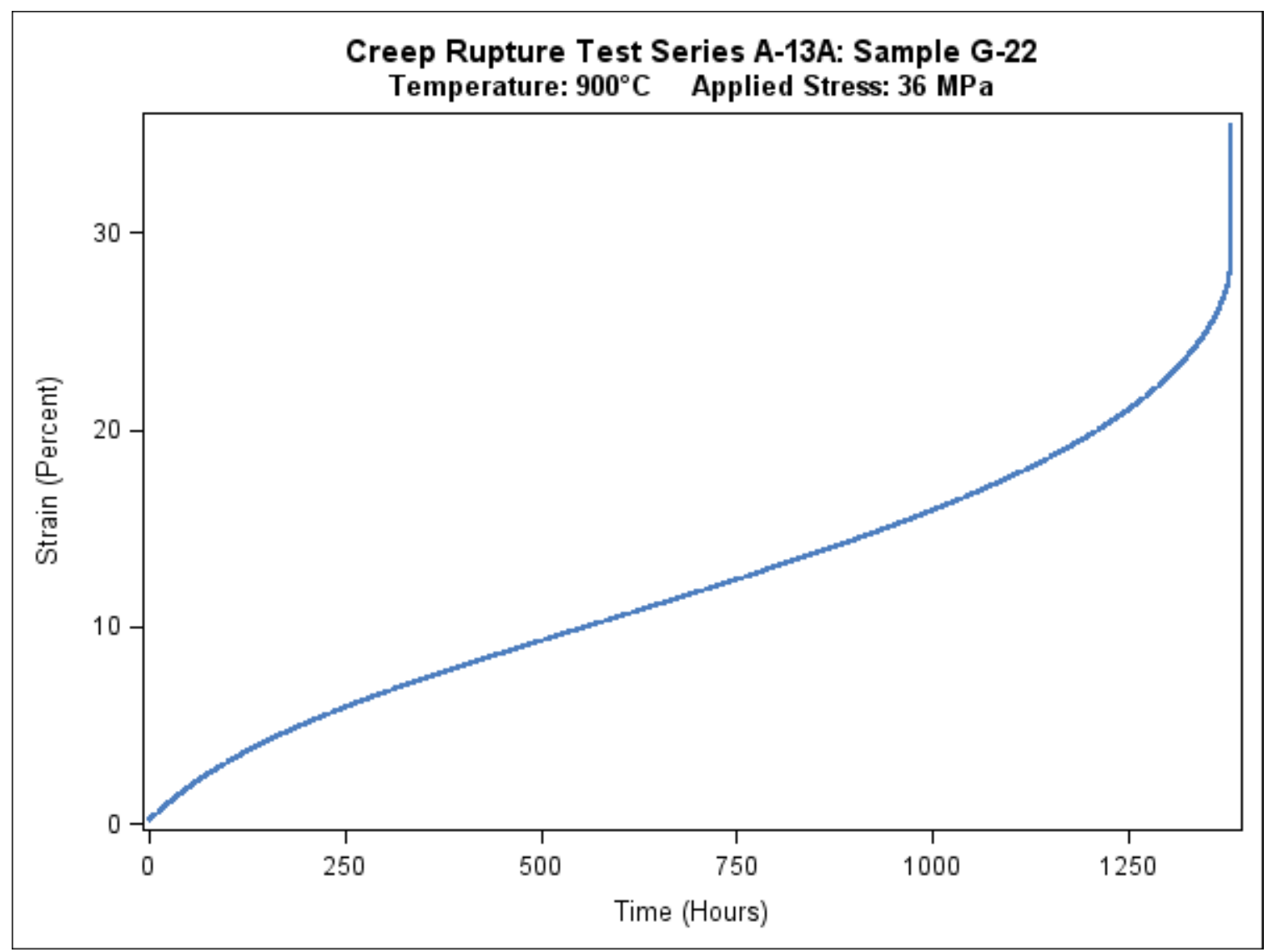

Figure 13. Results from creep-rupture tests performed on Alloy 617.

\subsubsection{SG\&IHX A-22 Interrupted Creep Tests}

The SG\&IHX A-22 tests were performed at INL. These tests were run until the sample reached a target creep value. The test results for each sample tested are delivered in one file. Depending on which test frame is used, the data is either an Excel file or a comma-separated-value file. File names include the sample name as well as temperature, applied stress, and target creep (e.g.,

G13_750C_145MPa_5\%_final.xls and 617-G-3, 1000C, 20MPa, 2\%.csv).

Manual verification of a random sample from the first data package processed is complete. A graph of strain versus time for Sample G-31 is presented in Figure 14. 


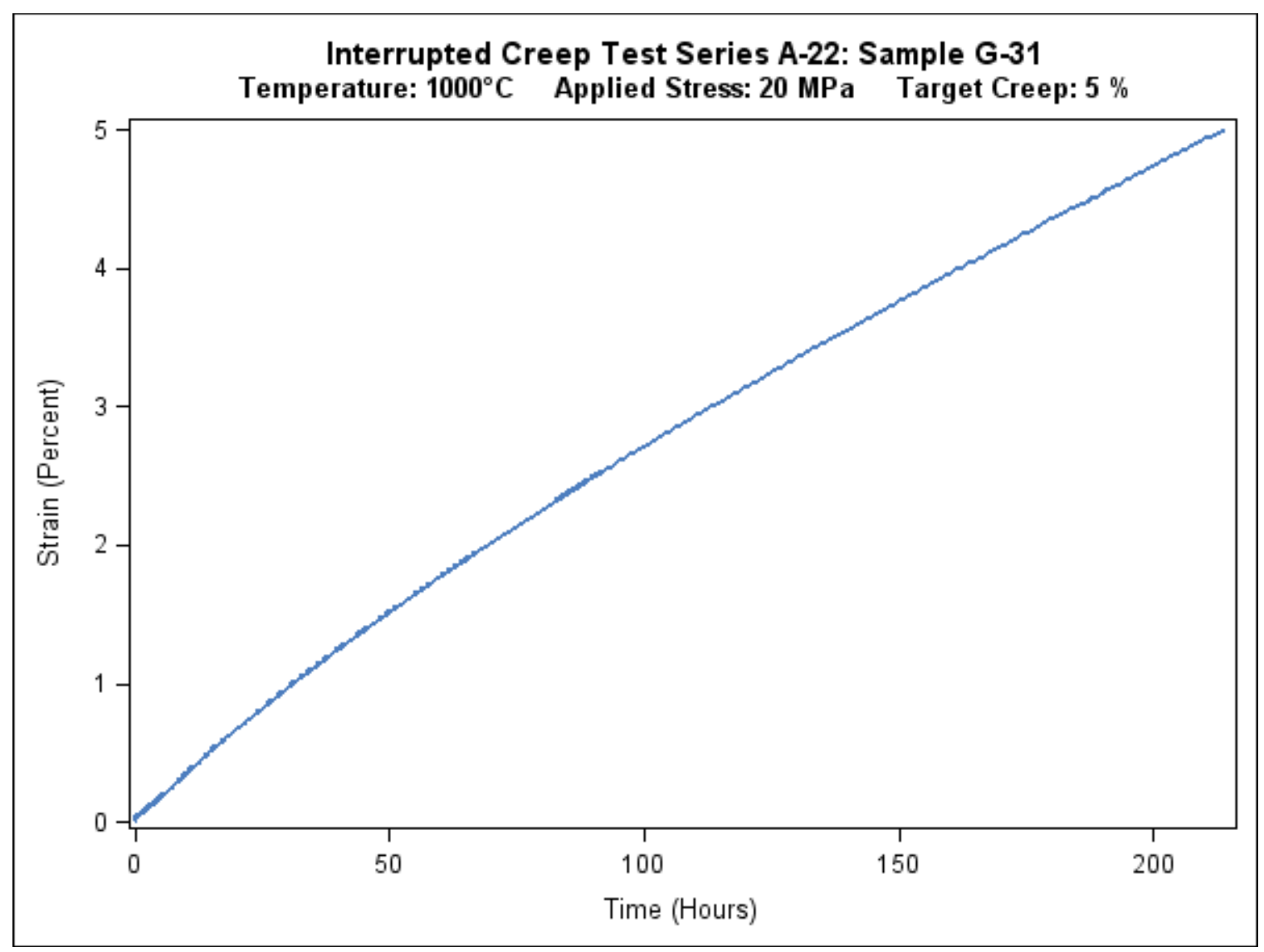

Figure 14. Results from interrupted creep tests of Ally 617.

\subsection{Description of HTM Data Qualification}

Two general types of qualification tests are performed on data loaded into NDMAS:

- Capture tests, which verify that data captured and stored within NDMAS are identical to the source data provided to NDMAS.

- Accuracy tests, which verify the data accurately represent the parameters they are intended to measure.

\subsubsection{Capture Tests}

A capture test is performed when the data is processed to verify that the data captured and stored within the NDMAS SQL database are identical to the source data provided to NDMAS. This test uses a SAS procedure (PROC-COMPARE) to compare the SAS dataset used as input to the SQL database with the SQL database output. Records of these test results are maintained for each HTM data package processed within NDMAS.

A manual verification is used to compare the SQL database output with the original data in the data packages. An independent person checks response variable values in the database against the data in the data packages and documents the results. This manual capture testing is performed for the first data package processed for each data processing code developed to ensure that the programming for the automatic processing is correct. 


\subsubsection{Accuracy Tests}

The accuracy of the HTM data will be verified by the HTM technical staff and documented using FRM-1073. The process of verifying that all data in the data packages meet specifications is a thorough process with multiple checks to ensure data accuracy. Because this process is so rigorous, no additional accuracy tests are planned for the HTM data. The data will be considered Qualified after successful completion and documentation (i.e., database logging) of both the NDMAS capture tests and approval of FRM-1073.

\subsection{HTM Data QA Documentation}

The NGNP data collection process includes plans describing how data will be collected and the QA activities associated with those data. Review of those plans assures that the work will generate data of appropriate quality for use in the NQA-1 program. Metadata generated by the initial documentation, audits, and acceptance inspection provide the evidence that data meet the requirements of an NQA-1 data collection program. This is documented by the test series within the HTM data stream. Documentation of the QA program implementation in NDMAS is primarily accomplished by references to documents. These include plans, audit reports, nonconformance reports, Engineering Design Files, and Engineering Calculations and Analysis Reports approved by the VHTR-TDO QA Lead. The documentation data collected by NDMAS will include a reference to a report explicitly listing the data qualification status for each data package.

The HTM data stream has separate test procedures for each type of testing. Currently, test procedures have been developed for tensile tests, creep-fatigue tests, and creep tests as follows:

- Tensile tests are governed by the tensile testing procedure (Chapman, et al., 2009) and the extensometer calibration procedure (Lloyd, et al., 2009). Accuracy tests are currently in development for the tensile data.

- Creep-Fatigue tests are governed by the creep-fatigue test procedure (Carroll, et al., 2010) and the extensometer calibration procedure (Lloyd, et al., 2009). Accuracy tests are currently in development for the creep-fatigue data.

- Creep tests are governed by the creep test procedure (Lillo, et al., 2010) and the extensometer calibration procedure(Lloyd, et al., 2009). Accuracy tests are currently in development for the creepdata.

Currently, the NDMAS vault has no qualified records for the HTM data stream (Table 6). All data have completed the initial capture test, and manual verification is complete for all records. 
Table 6. Qualification status of the HTM data currently entered in the NDMAS database.

\begin{tabular}{|c|c|c|}
\hline Test Series & Qualified Records & Total Records \\
\hline SG\&IHX A-1 & 0 & 1157755 \\
\hline SG\&IHX A-3 & 0 & 1403994 \\
\hline SG\&IHX A-13A & 0 & 136556 \\
\hline SG\&IHX A-20 & 0 & 1605155 \\
\hline SG\&IHX A-22 & 0 & 235279 \\
\hline RPV A-15 & 0 & 572790 \\
\hline RPV A-29 & 0 & 492153 \\
\hline Total & 0 & 5603682 \\
\hline
\end{tabular}

\subsection{HTM Data Problems and Resolution}

Minor discrepancies in the data files (e.g., incorrect column names) that were identified during data processing were resolved by conferring with the data producer. Any necessary changes were made to the archived data file within the subversion directory, with log entries to provide documentation. This provides traceability for the modifications, as well as the ability to recover the original data. 


\section{REFERENCES}

ASME, 2000, Quality Assurance Requirements for Nuclear Facility Applications, New York, NY, ASME International, Nuclear Quality Assurance (NQA-1), 2000.

Carroll, L. J. and Wright, R. N., 2010, “Creep Fatigue Testing,” PLN-3346, Idaho National Laboratory, Rev. 3, May 14, 2010.

Chapman, J. A. and Wright, R. N., 2009, “Tensile Testing,” PLN-3349, Idaho National Laboratory, November 4, 2009.

Hull, L. C. and Einerson, J. J., 2010, Very High Temperature Reactor Program Data Management and Analysis Plan, Idaho National Laboratory, PLN-2709, Rev. 2, June 23, 2010.

Lillo, T. M. and Wright, R. N. 2010, “Creep Testing.” PLN-3386, Idaho National Laboratory, January 27, 2010.

Roberts, G. D., and Trost, A L., 2009, "Very High Temperature Gas Reactor Technology Development Office Quality Assurance Program Plan, PLN-2690, Rev. 3, Idaho National Laboratory, December 9, 2009.

Wright, R. N., 2010a, "Next Generation Nuclear Plant Intermediate Heat Exchanger Materials Research and Development Plan," PLN-2804, Rev. 1, Idaho National Laboratory, September 23, 2010.

Wright, R. N., 2010b, "Next Generation Nuclear Plant Reactor Pressure Vessel Materials Research and Development Plan,” PLN-2803, Rev. 1, Idaho National Laboratory, July 14, 2010. 